\title{
Estratégias de melhoria do ambiente térmico diurno em situação de verão de uma fração urbana da cidade de São Paulo
}

\author{
Strategies for improving the daily thermal environment \\ of a urban fraction of the city of São Paulo in the summer
}

Flavia Cristina Osaku Minella
Programa de Pós Graduação em
Tecnilogia
Universidade Tecnológica Federal do
Paraná
Avenida Sete de Setembro, 3165,
Rebouças
Curitiba - PR - Brasil
CEP 80230-901
Tel.: (41) 3310-4725
E-mail: flavia.osaku@gmail.com

Susan Honjo

Institut des Sciences de l'Environnement Université de Genève

Site de Battelle 7, route de Drize, Bâtiment D,

1227 Carouge - Suisse Tel.: +(41) 223790797 E-mail: susan.honjo1602@gmail.com

Eduardo Leite Krüger Programa de Pós Graduação em
Tecnilogia Universidade Tecnológica Federal do Paraná

E-mail: ekruger@utfpr.edu.br

Recebido em 15/05/12

Aceito em 03/12/12

\section{Flavia Cristina Osaku Minella \\ Susan Honjo \\ Eduardo Leite Krüger}

\section{Resumo}

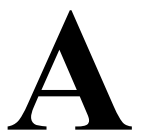

presente pesquisa visa a analisar o microclima em dois bairros com ocupação do solo diferenciada na cidade de São Paulo, as frações urbanas no Belém e no Jardim Paulista. Foram verificadas alterações no ambiente térmico na localidade menos vegetada a partir da introdução de arborização (no período diurno e sob condições de verão). Os dados microclimáticos foram obtidos por meio de medições simultâneas em campo no mês de fevereiro de 2011, totalizando 13 horas diurnas de medição em dois dias. A análise das variáveis microclimáticas relacionadas às características urbanas procura explicar as discrepâncias entre os ambientes térmicos de cada região. Por meio de simulações computacionais realizadas no programa ENVI-met, detectouse que a estratégia de arborização distribuída ao longo da via, em ambos os lados, pode reduzir na melhor situação em $1,8^{\circ} \mathrm{C}$ a temperatura do ar.

Palavras-chave: Ambiente térmico. Vegetação. ENVI-met. Simulações de clima urbano.

\section{Abstract}

The aim of this research work is to analyze microclimatic conditions in two districts with different land use in the city of São Paulo, the Belém and Jardim Paulista urban fractions. Changes in the thermal environment (during daytime and under summer conditions) of the less vegetated site were assessed by simulating an increase in the number of trees. Microclimate data were obtained by simultaneous field measurements in February 2011, totaling 13 hours of daytime measurements, carried out in two days. The analysis of variables related to the characteristics of urban microclimate has sought to explain the discrepancies between the thermal environments in each region. The results of the computer simulations, using the ENVI-met software, indicate that the strategy of distributed vegetation with trees along the street, on both sides, can reduce air temperature to $1.8^{\circ} \mathrm{C}$.

Keywords: Thermal environment. Vegetation. ENVI-met. Urban climate simulations. 


\section{Introdução}

São Paulo é considerada a quarta maior aglomeração urbana do mundo, com aproximadamente 20 milhões de habitantes (UNITED NATIONS, 2011), e mais de 11 milhões vivem na capital (INSTITUTO..., 2010). Por sua complexidade territorial, a cidade constitui-se num excelente campo de pesquisas para vários fenômenos urbanos, considerando impactos socioeconômicos e ambientais. No tocante ao processo histórico, observam-se, de um lado, as pressões advindas do crescimento populacional e, de outro, as propostas urbanísticas que objetivam conduzir, estruturar ou controlar a expansão urbana (SOMEKH, 2002).

$\mathrm{O}$ século XX foi marcado por grandes transformações sociais e econômicas, que resultaram em modificações na forma de utilização do espaço urbano. A partir de 1964, a verticalização da cidade, antes concentrada na área central, expandiu-se para os bairros pericentrais (ANTONUCCI, 2005). Quase simultaneamente ocorria um intenso processo de ocupação urbana em direção às periferias devido ao grande fluxo migratório. Em 1972, criou-se pela primeira vez uma Lei Geral de Zoneamento, no 7.805 (SÃO PAULO, 1972), para a cidade, abrangendo todas as suas regiões (FELDMAN, 2005). Segundo Macedo (1988), o modelo arquitetônico advindo do movimento moderno foi reforçado a partir dos parâmetros construtivos, com a consolidação de edificações de grande altura implantadas em lotes com pouco recuo em relação aos lotes vizinhos; tipologia de ocupação vertical reproduzida em muitas cidades brasileiras.

Ressalta-se que o crescimento desordenado e uma política ambiental ausente levaram a uma drástica redução da vegetação em São Paulo. Observa-se que a área urbana continua a expandir-se de maneira indevida, atingindo áreas de proteção a mananciais e afetando a qualidade ambiental. Segundo consta em São Paulo (2004), entre 1991 e 2000, a cidade reduziu 5,3 hectares de áreas verdes devido à ocupação urbana, estando $56 \%$ desse total concentrados em 10 distritos da periferia, onde existe um alto crescimento populacional.

Lombardo (1985) salienta que a urbanização desorganizada com redução de áreas verdes e predominância de materiais artificiais, como concreto e asfalto, na superfície urbana agrava a formação da ilha de calor urbana. Conforme Assis (2000), a produção desse fenômeno está associada ao efeito de transformação no balanço de energia da área urbana, influenciado não só pelas propriedades térmicas dos materiais utilizados em superfícies construídas, mas também pela morfologia urbana e pela produção antropogênica de calor, tanto em áreas temperadas quanto tropicais. Segundo Lombardo (1985), o fenômeno da ilha de calor é caracterizado, também, pelo aumento da precipitação convectiva nos ambientes urbanos mais aquecidos. A diferença de temperatura do ar entre a área central e seus arredores auxilia na formação de uma circulação convectiva, o que contribui para a concentração de poluentes nos centros urbanos (OKE, 1987). A associação desses fatores (aumento da temperatura urbana e poluição atmosférica) pode influir negativamente na saúde e na qualidade de vida da população. Estratégias podem ser utilizadas visando à qualidade térmica dos espaços citadinos, como, por exemplo, a utilização do albedo e da arborização urbana. Oke (1987) enfatiza a importância da vegetação na caracterização atmosférica local, na medida em que trocas sensíveis (radiação, convecção e condução) são substituídas por trocas úmidas (evapotranspiração), permitindo reduções na temperatura do ar.

Segundo estudo realizado por Freitas e Dias (2005), os maiores gradientes de temperatura do ar encontrados entre a área urbana de São Paulo e as áreas rurais atingiram valores superiores a $10{ }^{\circ} \mathrm{C}$ no período de inverno, com picos entre as $15 \mathrm{~h}$ e as 21h. Brandão (2009) procura estabelecer um método de avaliação da ambiência térmica urbana a fim de orientar as decisões de projeto e gestão nas cidades. Spangenberg et al. (2008) e Shinzato (2009) utilizaram simulações computacionais para verificar a influência da vegetação no campo térmico da área central de São Paulo.

Neste artigo o objetivo é analisar o microclima em duas frações urbanas com ocupação do solo diferenciada na cidade de São Paulo e verificar alterações no ambiente térmico na localidade menos vegetada, a partir da introdução de arborização (no período diurno e sob condições de verão).

\section{Metodologia}

Este estudo é apoiado em trabalho de campo e em simulações computacionais. A metodologia está assim dividida: apresenta-se primeiramente a área de estudo, em seguida a descrição do monitoramento em campo e, finalmente, os procedimentos para a simulação dos cenários hipotéticos. 


\section{Área de estudo}

O município de São Paulo é cortado pelo Trópico de Capricórnio, localizado a $23^{\circ} 37^{\prime}$ latitude sul e 46³9' longitude oeste; está a $802 \mathrm{~m}$ de altitude e em média a $45 \mathrm{~km}$ da costa, no planalto atlântico, sofrendo influência das condições oceânicas (TARIFA; AZEVEDO, 2001). A bacia do rio Tietê e seus afluentes, além da configuração topográfica, influencia na morfologia da cidade (SÃO PAULO, 2002). Conforme descrito em São Paulo (2002, p. 108), "este quadro físico define um conjunto de controles climáticos que, em interação com a sucessão habitual dos sistemas atmosféricos, propicia identidade aos climas locais" entre clima tropical úmido de altitude do planalto atlântico, clima tropical úmido serrano e clima tropical suboceânico.

A escolha inicial dos pontos de estudo foi baseada no mapa de temperatura aparente da superfície de São Paulo (Figura 1). Esse mapa, elaborado a partir de imagens do satélite Landsat 5TM, indica claramente a variação da temperatura de superfície (Ts) da aglomeração.

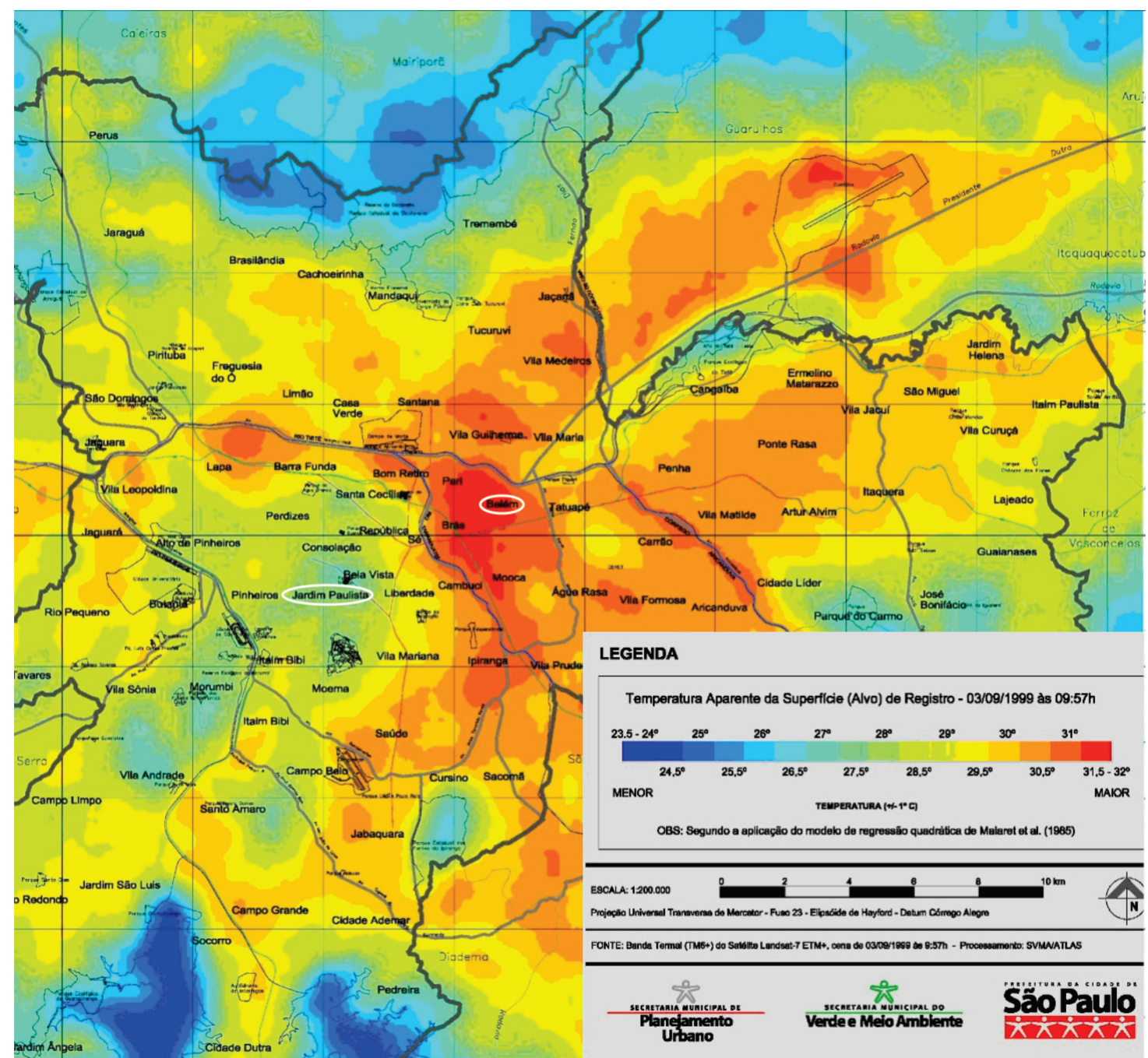

Figura 1 - Mapa da temperatura aparente da superfície (base satélite Landsat 5TM)

Fonte: São Paulo (2002). 
A área considerada crítica do ponto de vista térmico localiza-se na antiga região industrial da cidade. Observa-se que a ausência de espaços verdes e arborização urbana aliada a uma ocupação homogênea nessas regiões podem ser citadas como causas desse comportamento. Conforme descrito em São Paulo (2002), a influência dos materiais das coberturas das edificações contribui no aquecimento dessas regiões. A ocorrência de Ts mais amena localiza-se nas áreas com cobertura vegetal significativa: bairros onde predomina uma ocupação residencial horizontal com arborização intralote e viária, e junto aos corpos d'água. De acordo com dados de São Paulo (2002), a formação de algumas zonas frias é provocada pela projeção das sombras dos edifícios nas áreas com padrão de ocupação vertical em conjunto com outras variáveis, como uma melhor circulação do ar. A fim de analisar duas regiões com campos térmicos distintos, foram selecionadas frações urbanas no bairro Belém (Subprefeitura da Mooca, zona Leste), o qual se enquadra na primeira descrição, e no bairro Jardim Paulista (Subprefeitura de Pinheiros, zona Oeste), bairro com Ts mais favorável, conforme observado na
Figura 2. Os pontos de estudo nessas frações foram dispostos em locais com uma tipologia de edificação similar, composta de prédios de dois pavimentos sem recuo frontal (Figura 3).

O Jardim Paulista possui um perfil tanto residencial como comercial, com alta densidade demográfica, e está localizado em uma das regiões mais altas da cidade, com cotas variando entre 745 m e $750 \mathrm{~m}$ acima do nível do mar. No Belém, encontram-se instaladas, principalmente, fábricas e residências. $\mathrm{O}$ bairro está localizado na região centro-leste da cidade, com cotas variando entre $724 \mathrm{~m}$ e $730 \mathrm{~m}$.

A partir de dados do Dipro (DEPARTAMENTO..., 2010), foram desenvolvidas maquetes virtuais com o programa ArcGIS 9 das duas regiões, com o objetivo de evidenciar as diferenças na configuração urbana (Figura 4). Conforme observado na Figura 1, em setembro de 1999, às 9h57, enquanto no bairro Belém a temperatura de superfície (Ts) média situava-se entre 31,5 e $32^{\circ} \mathrm{C}$, no Jardim Paulista a Ts média situava-se entre $27 \mathrm{e}$ $27,5^{\circ} \mathrm{C}$. A Tabela 1 contém dados estatísticos das duas regiões.

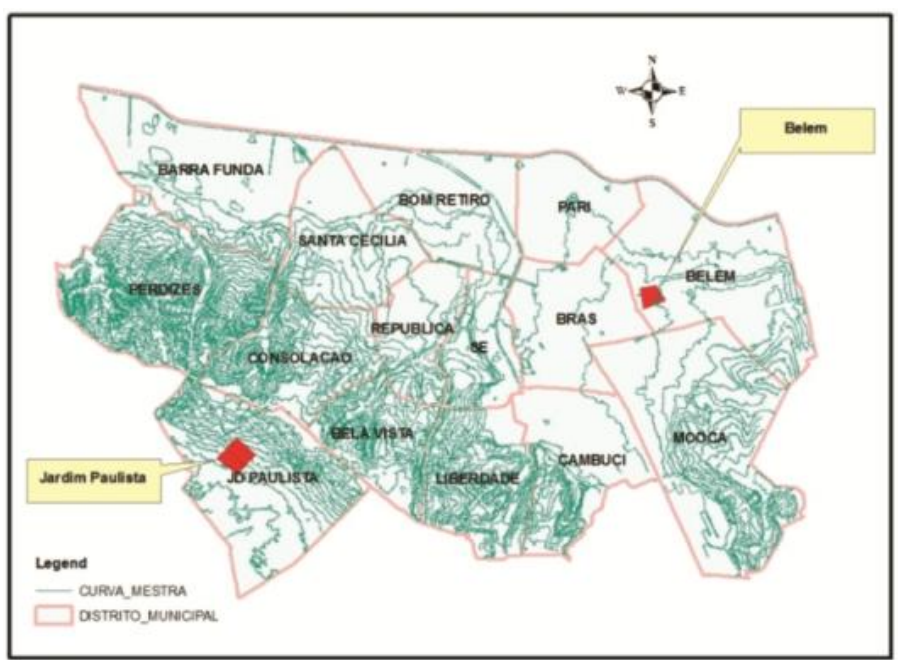

Figura 2 - Mapa de localização das áreas de estudo

Fonte: Departamento de Estatística e Produção de Informação (2010).

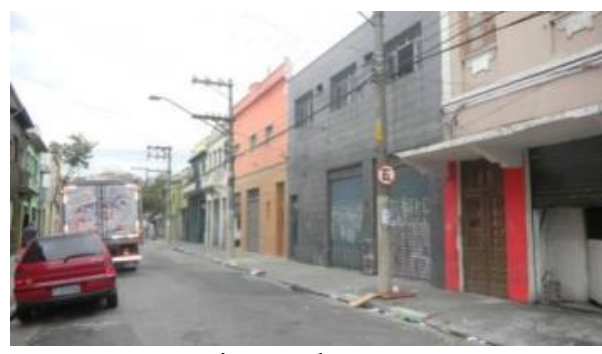

Bairro Belém

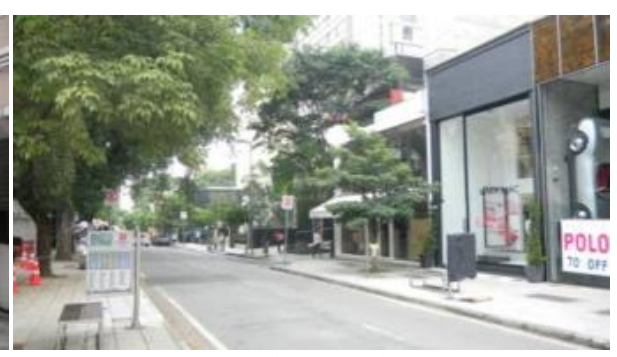

Bairro Jardim Paulista

Figura 3 - Áreas de estudo

142 Minella, F. C. O.; Honjo, S.; Krüger, E. L. 


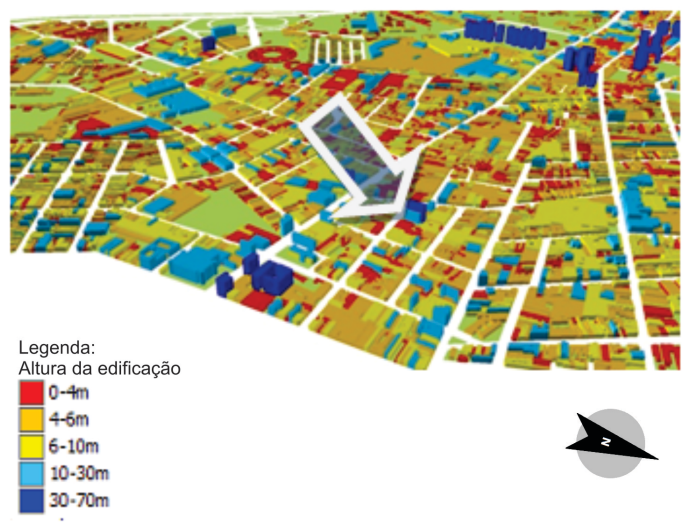

Bairro Belém

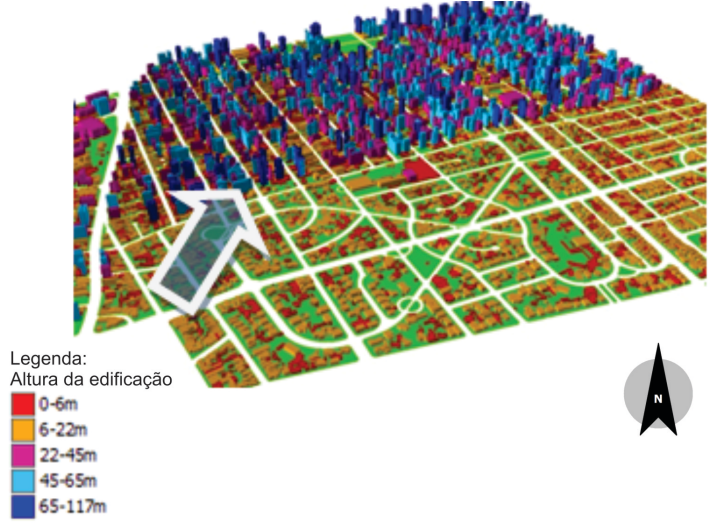

Bairro Jardim Paulista

Figura 4 - Perspectiva dos bairros Belém e Jardim Paulista e indicação dos locais de medição

Tabela 1 - Dados dos bairros Jardim Paulista e Belém

\begin{tabular}{l|c|c|c|c|c|c|c}
\hline \multicolumn{1}{c|}{ Bairro } & $\begin{array}{c}\text { Área } \\
\text { (ha) }\end{array}$ & $\begin{array}{c}\text { Cobertura } \\
\text { Vegetal } \\
\left(\mathbf{m}^{2}\right)\end{array}$ & $\begin{array}{c}\text { População } \\
\mathbf{( 2 0 0 0 )}\end{array}$ & $\begin{array}{c}\text { População } \\
\mathbf{( 2 0 0 9 )}\end{array}$ & $\begin{array}{c}\text { Densidade } \\
\text { demográfica } \\
(\mathbf{p o p} / \mathbf{h a}) \\
\mathbf{( 2 0 0 9 )}\end{array}$ & $\begin{array}{c}\text { Área de } \\
\text { terreno } \\
\mathbf{( m}^{\mathbf{2}} \mathbf{)} \\
(\mathbf{2 0 0 6})\end{array}$ & $\begin{array}{c}\text { Área } \\
\text { construída } \\
\mathbf{( m}^{\mathbf{2}} \mathbf{( \mathbf { 2 0 0 6 } )}\end{array}$ \\
\hline Jardim Paulista & 610 & 910.800 & 83.667 & 76.883 & 126,04 & 4.535 .765 & 12.897 .160 \\
\hline Belém & 600 & 416.700 & 39.622 & 36.505 & 60,84 & 4.159 .499 & 4.022 .090 \\
\hline
\end{tabular}

Fonte: Dipro (2010).

\section{Monitoramento em campo}

Os monitoramentos em campo nos dois pontos selecionados ocorreram simultaneamente, no período de verão. Os dados microclimáticos foram coletados de 1 em 1 min. As duas estações meteorológicas empregadas seguiram o mesmo critério de posicionamento: no passeio, junto à fachada voltada para o oeste, e o mais próximo possível da guia, de maneira a evitar a influência da radiação advinda das paredes das edificações. O período de medição no dia 22/02/2011 abrangeu 6 $\mathrm{h}$ de monitoramento (início às $9 \mathrm{~h} 01$ até as $15 \mathrm{~h} 00$ ). No dia 23/02/2011 o período de medição foi de $7 \mathrm{~h}$ (início às $7 \mathrm{~h} 01$ até as $14 \mathrm{~h} 00$ ). Em cada ponto foi utilizada uma estação meteorológica da marca HOBO modelo H21-001 (Figura 5).

Cada estação estava equipada com os seguintes instrumentos: sensor de temperatura e umidade (STHB-M002); piranômetro de silício (S-LIB-M003) e sensor de direção e velocidade do vento (SWCA-M003). As faixas de precisão desses instrumentos satisfazem as recomendações da norma ISO 7726 (INTERNATIONAL..., 1998), que dispõe sobre os instrumentos para a medição de variáveis físicas. Os sensores de temperatura do ar e umidade relativa foram fixados a $1,10 \mathrm{~m}$ do solo, conforme ISO 7726 (NTERNATIONAL..., 1998). O piranômetro foi fixado a $1,50 \mathrm{~m}$ acima dos demais sensores e orientado para o norte. $\mathrm{O}$ anemômetro foi fixado a 2,10 $\mathrm{m}$ do solo, conforme recomendado por Campbell (1997).

Para a obtenção da temperatura radiante média (Trm), foram utilizados termômetros de globo de cobre, com $\varnothing=2 "$, pintados na cor RAL-7001 (THORSSON et al., 2007), fixados em cada estação a 1,10 m do solo, conforme ISO 7726 (INTERNATIONAL..., 1998). A Trm foi calculada pela fórmula para convecção forçada, definida pela mesma norma. A temperatura de superfície em cada ponto foi obtida com termômetro de infravermelho em forma de pistola da marca RayTemp 38 a uma distância de 1,00 m do solo. A coleta de dados foi realizada a cada 30 min em quatro pontos prefixados ao redor da estação, sendo consideradas as médias aritméticas desses valores.

O índice de conforto utilizado neste estudo foi a temperatura fisiológica equivalente (PET) (HÖPPE, 1999), obtido por intermédio do RayMan, programa de domínio público desenvolvido por Matzarakis, Rutz e Mayer (2007). As informações pessoais foram baseadas nos dados de um homem padrão segundo a norma ISO 8996 (INTERNATIONAL..., 2004), considerando-se as seguintes características: idade 30 anos, altura $1,75 \mathrm{~m}$, e peso $70 \mathrm{~kg}$. A taxa metabólica utilizada foi de $110 \mathrm{~W}$, e o valor de isolamento térmico das roupas considerado foi de 0,5 clo (condição de verão). 
A Tabela 2 refere-se à calibração do índice PET para a cidade de São Paulo, realizada por Monteiro e Alucci (2007). O índice originalmente não apresenta faixas interpretativas, propondo-se que a avaliação seja feita em relação ao ambiente de referência.

A estação automática utilizada para as análises comparativas foi a Mirante de Santana, localizada na região norte da cidade. Os dados dessa estação de referência foram utilizados para verificar as diferenças no comportamento das variáveis climáticas entre os pontos monitorados e um ambiente com características diferentes do ambiente urbano, sendo obtidos na plataforma disponível online pelo Instituto Nacional de Meteorologia (Inmet, disponível em http://www.inmet.gov.br/sonabra/maps/automatica s.php). Foram considerados os dados referentes à hora UTC. O Inmet oferece os valores máximos e mínimos das variáveis climáticas; médias entre esses extremos foram extraídas para a comparação com os dados coletados em campo.

\section{Procedimentos para simulações}

O programa utilizado para simular estratégias de melhoria do ambiente térmico é o ENVI-met, desenvolvido Bruse e Fleer (1998), com base nas leis fundamentais da dinâmica dos fluidos e da termodinâmica, de modo a simular as interações microclimáticas no ambiente urbano nas três dimensões, com resolução padrão de $0,5 \mathrm{~m}$ até 10 $\mathrm{m}$ no espaço e de $10 \mathrm{~s}$ no tempo (BRUSE, 2012). O modelo serve, portanto, para prognosticar cenários urbanos, podendo ser aplicado na arquitetura, planejamento urbano e ambiental, e climatologia. O modelo inclui a simulação do processo de trocas térmicas entre superfícies, o fluxo de ar entre as edificações e turbulências, bem como a dispersão de particulados. ENVI-met é um software livre (disponível em http://www.envimet.com).

Basicamente, são requeridos dois arquivos para que o programa simule o ambiente urbano: um com a fração urbana de interesse modelada e outro com os dados para a definição da configuração inicial. A metodologia contém a explanação dessas duas etapas, assim como as descrições da etapa de ajuste do modelo e dos cenários hipotéticos. A versão mais atual do programa e utilizada neste estudo é o ENVI-met 3.1 Beta 5. Para a visualização dos dados em mapas térmicos utilizou-se a extensão Leonardo 3 do ENVI-met.

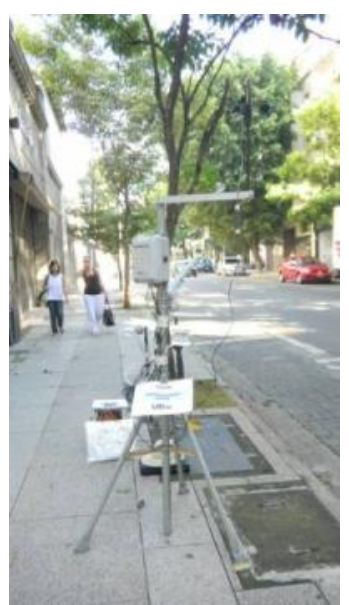

Figura 5 - Estação meteorológica (Jardim Paulista)

Tabela 2 - Proposição de calibração para o índice PET por Monteiro e Alucci (2007)

\begin{tabular}{c|c}
\hline Grau PET & Sensação humana \\
\hline$>43$ & Muito calor \\
\hline $31-43$ & Calor \\
\hline $26-31$ & Pouco calor \\
\hline $18-26$ & Neutra \\
\hline $12-18$ & Pouco frio \\
\hline $4-12$ & Frio \\
\hline
\end{tabular}

144 Minella, F. C. O.; Honjo, S.; Krüger, E. L. 


\section{Modelagem (edição de área)}

A fração urbana do Bairro Belém selecionada para o estudo consiste em seis quadras da Rua Firminiano Pinto e outras cinco quadras seccionadas, que completam um perímetro de aproximadamente $366 \mathrm{~m}$ no eixo x e de $390 \mathrm{~m}$ no eixo y. O tamanho do grid utilizado foi de $6 \mathrm{~m}$. Ressalta-se que, quanto menor o tamanho deste, mais detalhes podem ser incluídos no modelo, apresentando melhor resolução. No entanto, o tamanho final do domínio será maior; o que pode acarretar em uma demanda maior de tempo para rodar cada teste. Ainda na parte de modelagem, é requisitada a escolha do número de grids para a área de transição em torno do modelo ou área de aninhamento; no caso, foram escolhidos 3 grids, como também o tipo de solo dessa área.

Considerando a fração selecionada, a edificação mais alta possui $37 \mathrm{~m}$ de altura; a maior parte das edificações varia entre dois a cinco pavimentos (6 $\mathrm{m}$ a $15 \mathrm{~m}$ de altura). No ENVI-met a vegetação é caracterizada pela densidade de área foliar (Leaf Area Density - LAD), parâmetro definido pela relação entre a área total de folhas e o volume da copa $(\mathrm{m} 2 / \mathrm{m} 3)$, sendo a altura da árvore segmentada em 10 partes iguais. Entre a diversidade de vegetação disponível, foram escolhidos dois tipos de árvores para a região: árvores com copa densa de $20 \mathrm{~m}$ de altura (sigla DM - LAD para cada segmento: 0,075 0,075 0,075 0,075 0,250 1,150 1,060 1,050 0,920 0,000); e árvores com $15 \mathrm{~m}$ de altura (sigla 11 - LAD para cada segmento: $0,040 \quad 0,060 \quad 0,070 \quad 0,110 \quad 0,130$ $0,150 \quad 0,140 \quad 0,130 \quad 0,100 \quad 0,000)$. Para a representação da área de estudo foi utilizado um arquivo digital cedido pela Prefeitura Municipal de São Paulo com a planta das quadras contendo as implantações das edificações e suas respectivas alturas, combinado à imagem de satélite obtida no programa Google Earth. O modelo-base finalizado pode ser visualizado na Figura 6. O receptor P1 foi alocado na mesma quadra do ponto de coleta de dados. O tipo de solo utilizado na área modelada foi asfalto e concreto.

\section{Configuração dos dados de entrada}

O programa ENVI-met combina dados climáticos obtidos em várias alturas e, portanto, exige a utilização de diferentes fontes para a obtenção deles. $\mathrm{O}$ dado de umidade específica a $2.500 \mathrm{~m}$ de altura foi obtido no site referente a sondagens atmosféricas da Universidade de Wyoming (http://weather.uwyo.edu/upperair/sounding.html). Neste, são disponibilizados dados em dois horários: $0 \mathrm{Z}$ e $12 \mathrm{Z}$ (ou $21 \mathrm{~h} 00$ e $9 \mathrm{~h} 00$ ), sendo este último horário compreendido no período de coleta de dados em campo. As demais variáveis climáticas requisitadas para a inicialização do processo de simulação foram obtidas a partir da estação meteorológica de referência (Mirante de Santana). Os dados de temperatura inicial da atmosfera em graus Kelvin, umidade relativa a $2 \mathrm{~m}$ de altura e direção do vento referem-se aos dados registrados às $9 \mathrm{~h} 00$ (12h UTC). Já nos primeiros testes com o ENVI-met, foi observado que a velocidade do vento simulada no período de análise pouco se alterava a partir do dado de entrada, resultando em valores simulados próximos a este. Assim, para que os dados de velocidade de vento simulados fossem semelhantes aos coletados em campo, foi necessário reduzir o valor de $3,3 \mathrm{~m} / \mathrm{s}$ (registrado às $9 \mathrm{~h} 00$ ) para $1,7 \mathrm{~m} / \mathrm{s}$, correspondente ao valor médio diário.
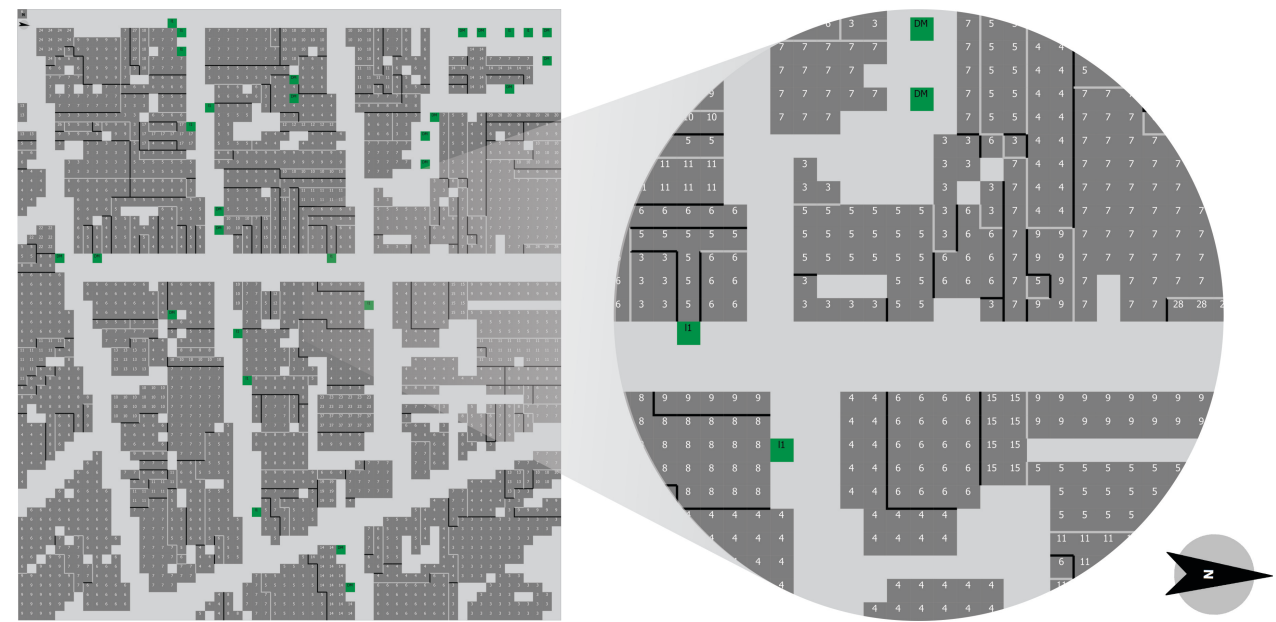

Figura 6 - Modelo-base da fração urbana do bairro Belém 
O comprimento de rugosidade (z0) das superfícies adotado foi de 0,1 , típico para áreas abertas com obstáculos ocasionais (WIERINGA et al., 2001). Em relação ao mecanismo de funcionamento da borda do modelo, para temperatura e umidade, optou-se pela opção na qual os dados do limite do modelo advêm dos dados dos grids próximos (open LBC). Para a energia cinética e taxa de dissipação (TKE), as opções de cálculo não apresentaram muita diferença, optando-se por aquela em que os dados do limite do modelo advêm do modelo unidimensional (forced).

Nos pré-testes realizados, os valores referentes às propriedades das edificações mostraram ter menos influência nos dados de saída do que as variáveis acima citadas, sendo utilizados os valores originais do programa.
Uma variável importante que pode ser inserida no programa ENVI-met refere-se à nebulosidade. Sabe-se que céu claro (sem nuvens) é a condição ideal de medição. No entanto, no mês de fevereiro de 2011 em São Paulo não foi possível obter dias com essa condição desejável. Dessa forma, foi necessário classificar a condição de céu dos dias medidos. Com auxílio do programa Excel preparado para a predição de radiação solar baseado no modelo paramétrico de Bird e Hulstrom (disponível em <ftp://epgftp.umaine.edu/VICTOR/solar_radiation $>$ ) foi calculada a radiação solar global sem a interferência de nuvens, sendo esta então comparada com a radiação solar medida (Figuras 7 e 8).

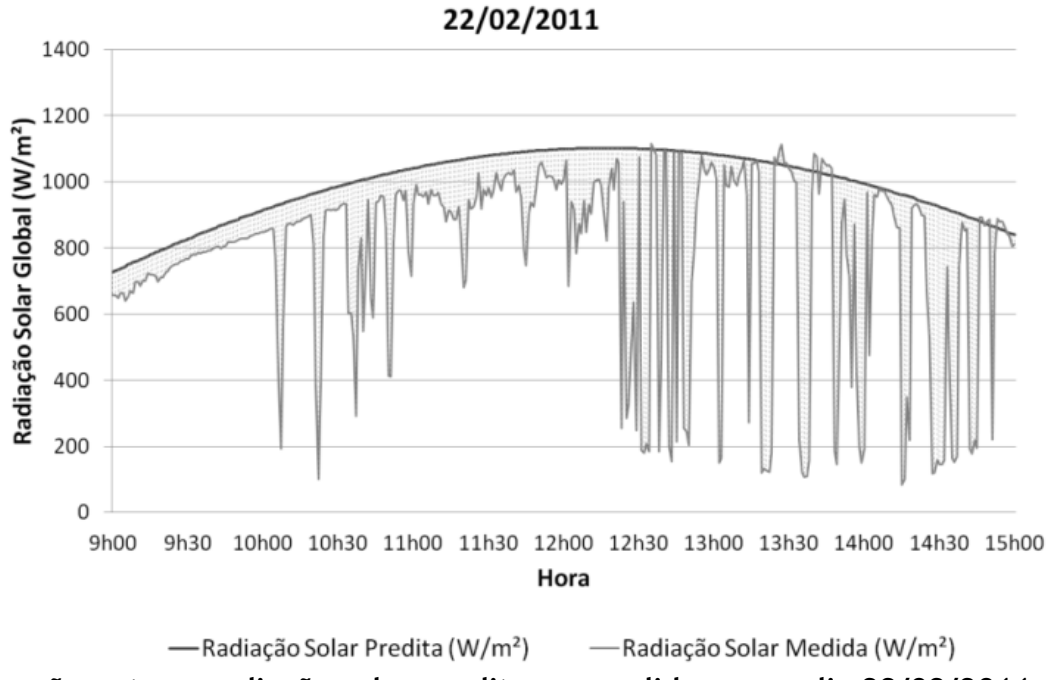

Figura 7 - Comparação entre a radiação solar predita e a medida para o dia 22/02/2011

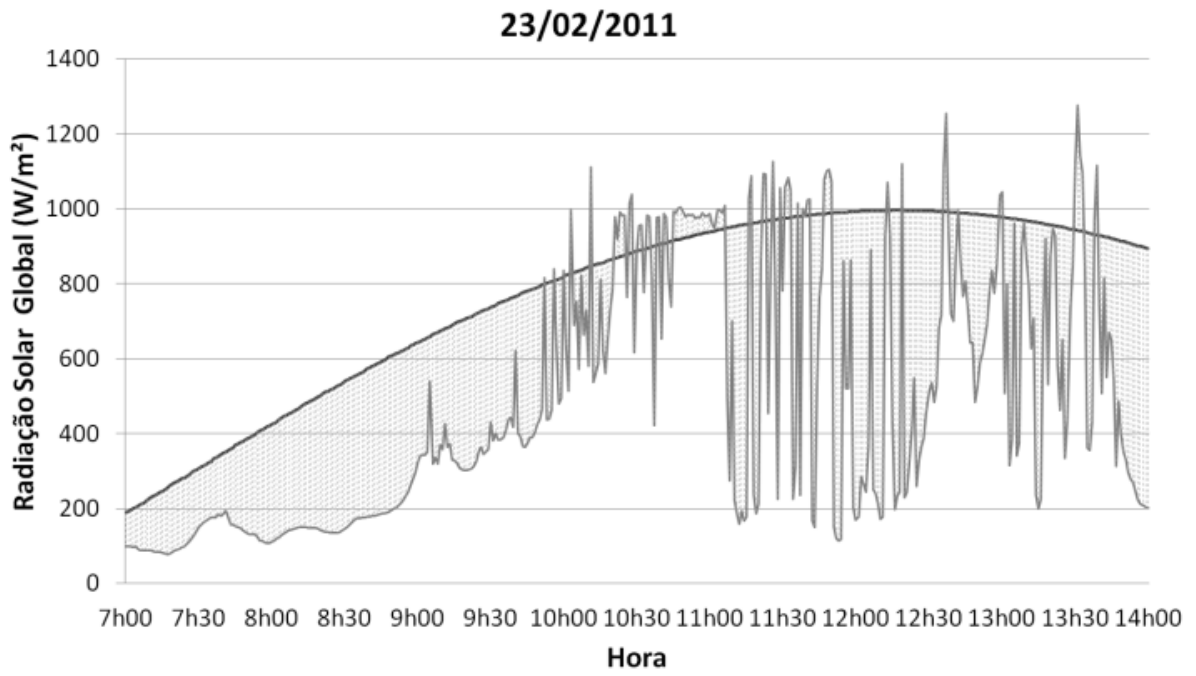

—Radiação Solar Predita $\left(\mathrm{W} / \mathrm{m}^{2}\right)$ —Radiação Solar Medida $\left(\mathrm{W} / \mathrm{m}^{2}\right)$

Figura 8 - Comparação entre a radiação solar predita e a medida para o dia 23/02/2011 
No Belém são observadas situações distintas para os dois dias de medição. No dia 22/02/2011, embora tenham ocorrido variações na radiação solar incidente, principalmente após as $12 \mathrm{~h} 30$, no início da medição a condição de céu era semiestável. O valor médio de radiação solar global no período medido foi de $772 \mathrm{~W} / \mathrm{m}^{2}$, enquanto o valor de radiação solar predito foi de $992 \mathrm{~W} / \mathrm{m}^{2}$, com diferença de $220 \mathrm{~W} / \mathrm{m}^{2}$ (Tabela 3 ). No dia 23/02/2011, no início da medição o céu estava encoberto, o que acarretou em valores baixos de radiação solar. $O$ valor médio de radiação solar global no período medido foi de 483 $\mathrm{W} / \mathrm{m}^{2}$, enquanto o valor de radiação solar predito foi de $857 \mathrm{~W} / \mathrm{m}^{2}$, com diferença de $374 \mathrm{~W} / \mathrm{m}^{2}$.

Para a classificação de nebulosidade foi realizado um cálculo em porcentagem de céu claro e utilizado o código Meteorological Aerodrome Report (METAR), disponível na internet $<$ http://www.redemet.aer.mil.br/index.php $>$, conforme a Tabela 4.

Segundo a classificação estabelecida, a condição de céu predominante no dia 22/02 foi céu com poucas nuvens, entre 1 e 2 oitavos $(78 \%$ de céu claro). No dia 23/02 a condição de céu predominante foi céu com nuvens esparsas, entre 3 e 4 oitavos ( $56 \%$ de céu claro).

A análise de nebulosidade revela que no dia 23/02 o céu parcialmente encoberto nas primeiras horas de medição influenciou na formação de uma curva de temperatura do ar atípica. Ao levar em conta dois parâmetros de referência para o ajuste do modelo, a temperatura do ar e a radiação solar global média no período monitorado, esse dia não apresenta condições suficientes para que seja simulado no programa ENVI-met. Assim, para o objetivo do estudo proposto foi considerado apenas o dia 22/02/2011.

Nos dados de configuração do programa é possível ajustar os dados de nuvens altas, médias e baixas. Devido à falta de informações mais precisas além do valor médio de fração de nuvem, optou-se em manter o valor zero, relativo a céu claro. Para que o valor de radiação solar global incidente fosse mais próximo dos valores medidos, utilizou-se a função de ajuste solar para ondas curtas (solar adjust), opção fornecida pelo programa, que varia de 0,5 até 1,0. Em suma, os dados de entrada configurados inicialmente foram os apresentados na Tabela 5.

Tabela 3 - Radiação solar global predita e medida

\begin{tabular}{|c|c|c|c|c|}
\hline \multirow[b]{2}{*}{ Hora } & \multicolumn{2}{|c|}{$22 / 02 / 2011$} & \multicolumn{2}{|c|}{$23 / 02 / 2011$} \\
\hline & $\begin{array}{l}\text { Radiação solar } \\
\text { predita }\left(\mathrm{W} / \mathbf{m}^{2}\right)\end{array}$ & $\begin{array}{l}\text { Radiação solar } \\
\text { medida }\left(W / \mathbf{m}^{2}\right)\end{array}$ & $\begin{array}{l}\text { Radiação solar } \\
\text { predita }\left(W / \mathbf{m}^{2}\right)\end{array}$ & $\begin{array}{l}\text { Radiação solar } \\
\text { medida }\left(W / \mathbf{m}^{2}\right)\end{array}$ \\
\hline $8 \mathrm{~h} 00$ & - & - & 365 & 122 \\
\hline $9 \mathrm{~h} 00$ & - & - & 614 & 171 \\
\hline $10 \mathrm{~h} 00$ & 827 & 760 & 825 & 409 \\
\hline $11 \mathrm{~h} 00$ & 984 & 776 & 982 & 848 \\
\hline $12 \mathrm{~h} 00$ & 1077 & 953 & 1075 & 650 \\
\hline $13 \mathrm{~h} 00$ & 1097 & 766 & 1095 & 589 \\
\hline $14 \mathrm{~h} 00$ & 1044 & 727 & 1041 & 589 \\
\hline $15 \mathrm{~h} 00$ & 921 & 649 & - & - \\
\hline Média & 992 & 772 & 857 & 483 \\
\hline
\end{tabular}

Tabela 4 - Classificação de nebulosidade

\begin{tabular}{l|l|l|l|l}
\hline \multicolumn{1}{c|}{ Sigla } & \multicolumn{1}{c|}{ Classificação } & Oitavas & \multicolumn{1}{c|}{ Porcentagem de céu claro } & \multicolumn{1}{c}{ Sigla } \\
\hline FEW & Poucas nuvens & 1 a 2 & 100 a 76 & FEW \\
\hline SCT & Nuvens esparsas & 3 a 4 & 75 a 51 & SCT \\
\hline BKN & Nublado & 5 a 7 & 50 a 13 & BKN \\
\hline OVC & Encoberto & 8 & 12 a 0 & OVC \\
\hline
\end{tabular}

Tabela 5 - Configuração inicial do modelo

\begin{tabular}{l|c}
\hline \multicolumn{1}{c|}{ Variável } & $\mathbf{2 2 / 0 2 / 2 0 1 1}$ \\
\hline Velocidade do vento (10 m de altura) & $1,7 \mathrm{~m} / \mathrm{s}$ \\
\hline Direção do vento (10 m de altura) & 0 graus \\
\hline Temperatura do ar (2 m de altura) & $297 \mathrm{~K}$ \\
\hline Umidade relativa do ar (2 m de altura) & $68 \%$ \\
\hline Umidade específica (aproximadamente a $2.500 \mathrm{~m}$ de altura) & $7 \mathrm{~g} / \mathrm{kg}$ \\
\hline Comprimento de rugosidade & 0,1 \\
\hline Ajuste solar para ondas curtas & 0,8 \\
\hline
\end{tabular}




\section{Ajustes do modelo ENVI-met}

Para o ajuste do modelo foram estabelecidas duas variáveis de referência, a temperatura do ar e a radiação solar global. Testes estatísticos apontaram a curva com temperatura do ar mais fidedigna à temperatura do ar obtida nos monitoramentos, sendo aplicados os seguintes testes: o erro médio quadrático (Root Mean Squared Error, RMSE), o índice de concordância de Willmott (Willmott index of agreement) e o teste $t$-Student.

O RMSE e o índice de concordância de Willmott (d) indicam a exatidão do método, isto é, o afastamento entre os valores preditos e os medidos. No RSME o valor ideal é o mais próximo de zero. O índice de concordância de Willmott varia de zero a 1 , sendo este último a concordância ideal. As Equações 1 e 2 descrevem esses testes, respectivamente.

$R S M E=\sqrt{\frac{\sum_{i=1}^{n}\left(y_{i}-x_{i}\right)^{2}}{n}}$

$d=1-\frac{\sum_{i=1}^{n}\left(y_{i}-x_{i}\right)^{2}}{\sum_{i=1}^{n}\left(\left|y_{i}-x\right|+\left[\left|x_{i}-x\right|\right)^{2}\right.}$

Onde:

yi = é a temperatura predita;

$\mathrm{xi}=$ é a temperatura medida; e $\mathrm{n}=$ número de observações.

$\mathrm{O}$ teste $t$-Student é utilizado quando se pretende comparar duas médias, sendo adotado um nível de significância de 0,05 .

Por se tratar de um modelo de simulação numérica, sabe-se que o programa exige determinado número de horas (ou dias) para a estabilização dos dados. Para a determinação desse tempo requerido foi simulado o mesmo dia diversas vezes consecutivas. São apresentados na Tabela 6 os resultados de convergência obtidos até o décimo primeiro dia de simulação. Nessa tabela também estão contidos os valores médios de radiação solar global e os resultados dos testes estatísticos aplicados.

Para o dia 22/02/2011, o teste $t$-Student mostra que a partir da curva 8 , correspondente ao oitavo dia consecutivo, não há mais diferença significativa (valor $\mathrm{p}<0,05)$ entre os valores de temperatura do ar preditos e os valores medidos. A curva 11 (décimo primeiro dia de simulação) foi a que apresentou maior semelhança com a curva medida: a estimativa de erro médio quadrático foi de 0,91 , e o índice de concordância de Wilmott foi de 0,94 . A diferença entre a radiação solar predita e a medida foi de $104 \mathrm{~W} / \mathrm{m}^{2}$.

Tabela 6 - Testes estatísticos para o dia 22/02/2011

\begin{tabular}{l|c|c|c|c|c|c|c|c|c|c|c}
\hline \multicolumn{1}{c|}{ Resumo } & $\begin{array}{c}\text { curva } \\
1\end{array}$ & $\begin{array}{c}\text { curva } \\
2\end{array}$ & $\begin{array}{c}\text { curva } \\
3\end{array}$ & $\begin{array}{c}\text { curva } \\
4\end{array}$ & $\begin{array}{c}\text { curva } \\
5\end{array}$ & $\begin{array}{c}\text { curva } \\
6\end{array}$ & $\begin{array}{c}\text { curva } \\
7\end{array}$ & $\begin{array}{c}\text { curva } \\
8\end{array}$ & $\begin{array}{c}\text { curva } \\
9\end{array}$ & $\begin{array}{c}\text { curva } \\
10\end{array}$ & $\begin{array}{c}\text { curva } \\
11\end{array}$ \\
\hline $\begin{array}{l}\text { Ta média } \\
\left.\text { predita ( }{ }^{\circ} \mathbf{C}\right)\end{array}$ & 27,5 & 28,4 & 28,7 & 28,7 & 29,0 & 29,4 & 29,9 & 30,4 & 30,5 & 30,6 & 30,6 \\
\hline $\begin{array}{l}\left.\text { Ta ( }{ }^{\circ} \mathbf{C}\right)- \\
\text { erro médio } \\
\text { (medida } \\
\text { predita) }\end{array}$ & 3,7 & 2,8 & 2,6 & 2,6 & 2,3 & 1,8 & 1,4 & 0,9 & 0,8 & 0,7 & 0,6 \\
\hline RMSE & 3,77 & 2,94 & 2,69 & 2,69 & 2,41 & 1,98 & 1,55 & 1,13 & 1,03 & 0,95 & 0,91 \\
\hline $\begin{array}{l}\text { Willmott } \\
\text { index of } \\
\text { agreement }\end{array}$ & 0,57 & 0,64 & 0,67 & 0,67 & 0,71 & 0,77 & 0,84 & 0,9 & 0,92 & 0,93 & 0,94 \\
\hline $\begin{array}{l}\text { teste t (valor } \\
\text { p) }\end{array}$ & 0,00 & 0,00 & 0,00 & 0,00 & 0,00 & 0,00 & 0,01 & 0,05 & 0,07 & 0,1 & 0,13 \\
\hline $\begin{array}{l}\text { Ig (W/m } \mathbf{m}^{2} \text { ) } \\
\text { valor médio } \\
\text { (medida } \\
\text { predita) }\end{array}$ & 857 & 863 & 865 & 867 & 870 & 873 & 874 & 875 & 875 & 876 & 876 \\
\hline $\begin{array}{l}\text { Ig (W/m } \\
\text { erro médio } \\
\text { (medida } \\
\text { predita) }\end{array}$ & 85 & 91 & 93 & 95 & 98 & 101 & 102 & 103 & 103 & 104 & 104 \\
\hline
\end{tabular}

148 Minella, F. C. O.; Honjo, S.; Krüger, E. L. 
Na Figura 9 é possível visualizar que é também a partir da curva 8 que os dados de temperatura do ar apresentam maior convergência, sendo este o tempo de iteração mínimo necessário para aquela localidade. A curva que apresenta maior semelhança estatística (curva 11) e a curva de temperatura do ar medida aparecem em destaque.

Para a verificação de estratégia de melhoria do ambiente térmico, é utilizada a curva 11 , às $15 \mathrm{~h} 00$, momento no qual a diferença entre a Ta medida e a predita é de $0,3{ }^{\circ} \mathrm{C}$, e quando a temperatura do ar atinge seu valor máximo no dia e período simulado.

\section{Cenários hipotéticos}

Visando à melhoria do ambiente térmico, foi considerada a inserção de árvores de $15 \mathrm{~m}$ de altura com copa densa e sem folhas na base (sigla T2 - LAD para cada segmento: 0,000 0,000 2,180 2,180 2,180 2,180 2,180 2,180 1,720 0,000), sendo estabelecidos dois cenários hipotéticos:

(a) cenário 1: inserção de arborização somente de um lado da rua; e

(b) cenário 2: inserção de arborização nos dois lados da rua, formando um corredor verde.

Ressalta-se que a intenção é verificar o efeito positivo da inserção de vegetação, e não indicar uma espécie de árvore.

\section{Resultados}

\section{Análise das variáveis climáticas}

A análise preliminar dos dois pontos de medição referente a um período diurno específico é apresentada nesta seção. A Tabela 7 contém as médias horárias de temperatura do ar (Ta), umidade relativa (UR), velocidade do vento (v) e radiação solar global incidente (Ig) e as respectivas correlações $(\mathrm{R})$ dessas variáveis com a temperatura do ar, para que se fizesse um primeiro teste de consistência dos dados.

No dia analisado $(22 / 02 / 2011)$ e nos dois pontos monitorados a variável climática que apresentou maior correlação com a temperatura do ar foi a umidade relativa do ar, numa relação inversa; fator relacionado à relação psicrométrica para conteúdo de umidade com pouca variação.

A correlação com a velocidade do vento também foi expressiva em ambos os casos e igualmente inversa: quanto maior a velocidade, mais baixa a temperatura ambiente.

Devido às características urbanas de cada localidade, o ponto situado no Belém apresentou valores de Ta, v e Ig e mais elevados que o ponto no Jardim Paulista.

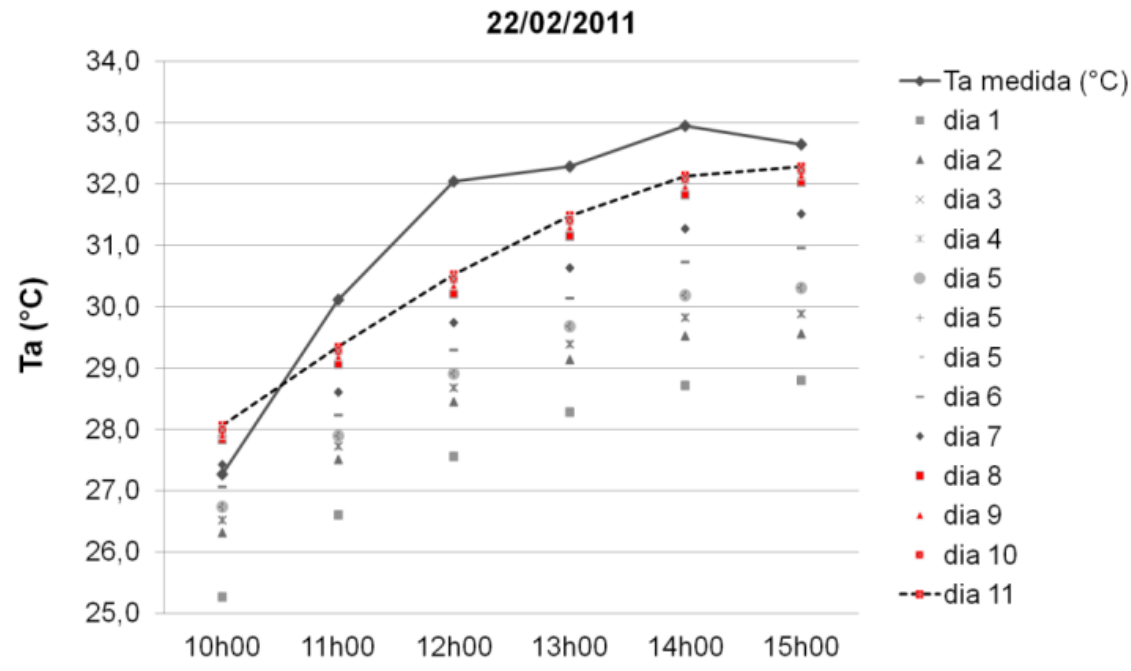

Figura 9 - Curva com maior semelhança com a Ta medida 
Tabela 7 - Médias horárias de temperatura do ar (Ta), umidade relativa (UR), velocidade do vento (v) e radiação solar global incidente $(\mathbf{l g})$, dados obtidos em campo

\begin{tabular}{l|c|c|c|c|c|c|c|c}
\hline \multicolumn{1}{c|}{ Data/Hora } & \multicolumn{3}{|c|}{ Jardim Paulista } & \multicolumn{3}{c}{ Belém } \\
\hline $\mathbf{2 2 / 0 2 / 2 0 1 1}$ & $\mathbf{T a}\left({ }^{\circ} \mathbf{C}\right)$ & UR (\%) & $\mathbf{v}(\mathbf{m} / \mathbf{s})$ & $\begin{array}{c}\mathbf{I g} \\
\left(\mathbf{W} / \mathbf{m}^{\mathbf{2}}\right)\end{array}$ & $\mathbf{T a}\left({ }^{\circ} \mathbf{C}\right)$ & $\mathbf{U R}(\mathbf{\%})$ & $\mathbf{v}(\mathbf{m} / \mathbf{s})$ & $\begin{array}{c}\mathbf{I g} \\
\left(\mathbf{W} / \mathbf{m}^{\mathbf{2}}\right)\end{array}$ \\
\hline $10 \mathrm{~h} 00$ & 26,7 & 62 & 0,9 & 114 & 27,3 & 61 & 1,7 & 760 \\
\hline $11 \mathrm{~h} 00$ & 27,8 & 57 & 0,7 & 59 & 30,1 & 53 & 1,4 & 776 \\
\hline $12 \mathrm{~h} 00$ & 29,0 & 55 & 0,7 & 61 & 32,0 & 47 & 1,1 & 953 \\
\hline $13 \mathrm{~h} 00$ & 30,0 & 52 & 0,7 & 90 & 32,3 & 47 & 1,4 & 766 \\
\hline $14 \mathrm{~h} 00$ & 30,8 & 48 & 0,7 & 99 & 32,9 & 44 & 1,2 & 727 \\
\hline $15 \mathrm{~h} 00$ & 30,9 & 48 & 0,6 & 78 & 32,6 & 44 & 1,4 & 649 \\
\hline Média & $\mathbf{2 9 , 2}$ & $\mathbf{5 4}$ & $\mathbf{0 , 7}$ & $\mathbf{8 4}$ & $\mathbf{3 1 , 2}$ & $\mathbf{4 9}$ & $\mathbf{1 , 4}$ & $\mathbf{7 7 2}$ \\
\hline $\begin{array}{l}\text { Correlação } \\
\text { (R) com Ta }\end{array}$ & - & $\mathbf{- 0 , 9 8}$ & $\mathbf{- 0 , 8 7}$ & $\mathbf{- 0 , 1 0}$ & - & $\mathbf{- 1 , 0 0}$ & $\mathbf{- 0 , 8 2}$ & $\mathbf{- 0 , 0 6}$ \\
\hline
\end{tabular}

Os valores de PET calibrados para a cidade de São Paulo por Monteiro e Alucci (2007) indicam a sensação térmica em cada ponto, sendo as sensações divididas por faixas:

(a) 18 a $26^{\circ} \mathrm{C}$ : neutralidade;

(b) 26 a $31^{\circ} \mathrm{C}$ : pouco calor; e

(c) 31 a $43{ }^{\circ} \mathrm{C}$ : calor e maior que $43{ }^{\circ} \mathrm{C}$ muito calor.

No Belém, o desconforto térmico é visivelmente mais significativo do que no Jardim Paulista (Figura 10). No dia analisado, a sensação térmica predominante foi de calor, com $74,2 \%$, atingindo até a faixa de muito calor, com $25,8 \%$. No Jardim Paulista a variação foi entre neutralidade térmica $(16,7 \%)$, predominando em pouco calor $(73,3 \%)$, e $10 \%$, atingindo a faixa de calor. Observa-se no ponto do Jardim Paulista que o desconforto para calor tende a elevar-se de forma mais gradual.

A análise das variáveis climáticas relacionadas às características urbanas de cada área auxilia o entendimento das discrepâncias entre os ambientes térmicos de cada localidade. A Figura 11 apresenta as comparações entre as diferenças dos valores médios horários de Ta coletados em campo com a estação de referência $(\Delta \mathrm{Ta})$ e as médias horárias de
Ta em cada ponto. Durante todo o monitoramento, o ponto situado no Belém apresentou valores mais altos de Ta que o ponto no Jardim Paulista. Comparada à estação de referência, nota-se uma maior diferença de Ta com a região do Belém, principalmente após as $12 \mathrm{~h} 00$. Nesse período, ocorreu a diferença máxima de temperatura do ar $\left(3,2{ }^{\circ} \mathrm{C}\right)$ entre os pontos no Belém e no Jardim Paulista. No Belém o valor máximo de Ta registrada ocorreu às $14 \mathrm{~h} 00$, com $32,9{ }^{\circ} \mathrm{C}$, enquanto no mesmo dia, no Jardim Paulista, a máxima foi de $30,9^{\circ} \mathrm{C}$ no horário seguinte.

$\mathrm{O}$ valor menos intenso de $\Delta \mathrm{Ta}$ no Jardim Paulista em relação ao ponto no Belém é justificado principalmente pela presença de vegetação arbórea, que forma uma obstrução (parcial) à radiação solar. Percebe-se na Figura 12 a discrepância entre os valores de radiação solar global em cada ponto medido com a estação oficial $(\Delta \mathrm{Tg})$. A diferença média de radiação solar global, positiva para os dois pontos, foi de $75 \mathrm{~W} / \mathrm{m}^{2}$ no Belém, enquanto no Jardim Paulista a diferença foi de $137 \mathrm{~W} / \mathrm{m}^{2}$. Novamente, nota-se a influência da arborização para o favorecimento de um maior grau de conforto térmico em situações com temperaturas altas no período de verão. 


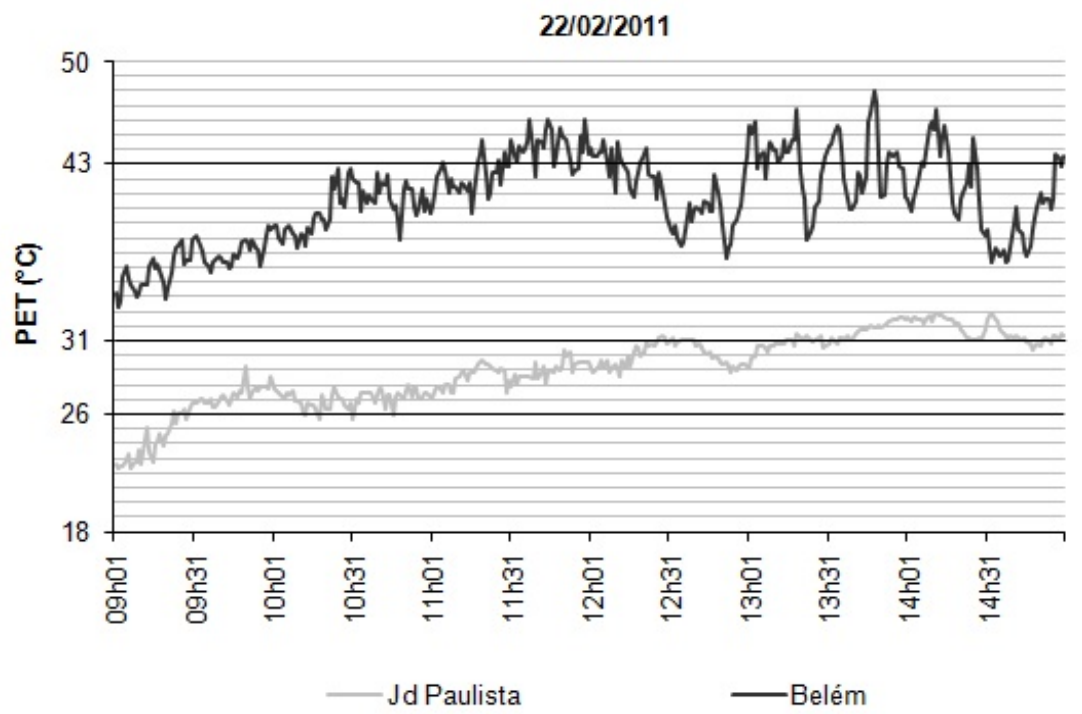

Figura 10 - Comparações dos valores de PET em cada ponto

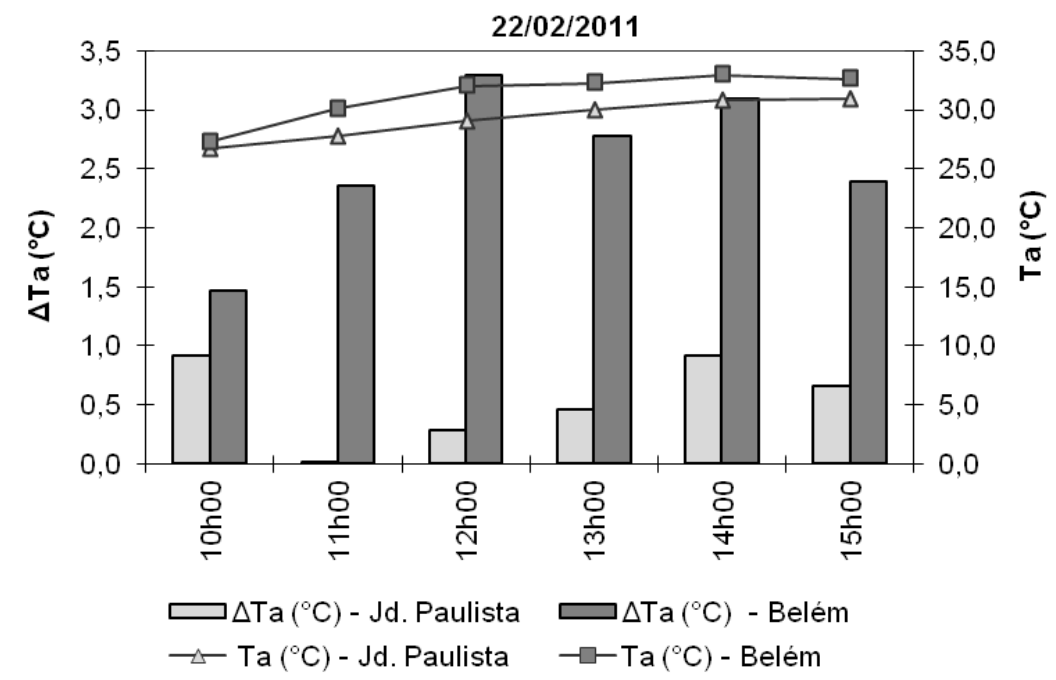

Figura 11 - Comparação entre os valores de $\Delta \mathrm{T}_{\mathrm{a}}$ e $\mathrm{Ta}$

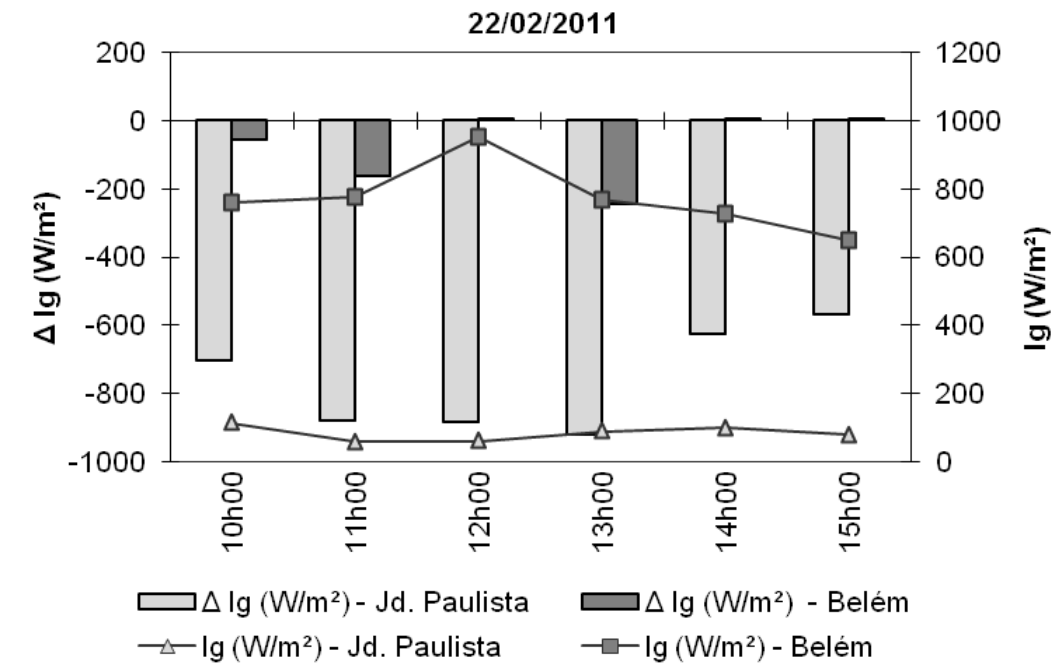

Figura 12 - Comparação entre os valores de $\Delta \mathrm{l}_{\mathrm{g}}$ e lg 
As diferenças na quantidade de vegetação arbórea influenciam os valores mais baixos de umidade relativa (45\%) no Belém (Tabela 3 ), comparado ao Jardim Paulista (54\%). A presença de árvores parece ser determinante, também, para uma menor velocidade do vento na região do Jardim Paulista, com diferença média de $0,7 \mathrm{~m} / \mathrm{s}$ entre um ponto e outro. Por meio da análise dos gráficos acima, nota-se a importância do sombreamento e da presença da arborização urbana para a formação do campo térmico local. Na Figura 13 encontram-se os valores de temperatura de superfície (Ts) medidos a 1,0 m de altura. A região do Belém apresenta valores mais altos de Ts, com mais de 47 ${ }^{\circ} \mathrm{C}$ às $13 \mathrm{~h} 30$ e média superior a $35^{\circ} \mathrm{C}$. Os valores de Ts no Jardim Paulista mantiveram-se mais constantes, com pico próximo a $28{ }^{\circ} \mathrm{C}$ e média de mais de $26^{\circ} \mathrm{C}$.

No mapa da temperatura aparente da superfície (Figura 1) é possível perceber que, durante o período próximo das $10 \mathrm{~h} 00$, a diferença aproximada de Ts para a região do Belém e a região do Jardim Paulista era cerca de $4{ }^{\circ} \mathrm{C}(31,5$ ${ }^{\circ} \mathrm{C}$ e $27,5^{\circ} \mathrm{C}$ respectivamente). A diferença de Ts obtida durante a coleta de dados em campo, no mesmo horário, foi de $10,2^{\circ} \mathrm{C}\left(36,5^{\circ} \mathrm{C}\right.$ no Belém e $26,3{ }^{\circ} \mathrm{C}$ no Jardim Paulista). Ressalta-se que as diferenças nos valores encontrados são provavelmente provenientes das diferentes metodologias aplicadas. No entanto, ambos os resultados evidenciam a tendência de valores de Ts mais altos no Belém. As discrepâncias nos valores medidos de Ts acentuam-se ao longo do dia, atingindo a diferença máxima de $19,0{ }^{\circ} \mathrm{C}$ às $13 \mathrm{~h} 30$.

\section{Estratégias de melhoria do ambiente térmico}

A estratégia de melhoria do ambiente térmico por meio do uso da arborização apresenta a vantagem do custo relativamente baixo e da possibilidade de ser aplicada na prática. Em comparação ao cenário original, sem modificação (Figura 14a), neste estudo são testados dois cenários alternativos:

(a) arborização em um lado da rua (Figura 14b); e

(b) arborização em ambos os lados (Figura 14c).

No cenário original a porcentagem de área construída corresponde a $62 \%$. Considerando toda a área simulada, as porcentagens de vegetação nos cenários 1 e 2 são de $1 \%$ e $2 \%$ respectivamente. Considerando apenas o trecho da rua de estudo (via e passeios), a porcentagem de vegetação no cenário 1 corresponde a $22 \%$, sendo o dobro no cenário 2 (44\%). A Figura 8 corresponde à imagem em três dimensões dos cenários analisados. As árvores não aparecem na imagem gráfica, para que seja possível uma melhor visualização do campo térmico. $\mathrm{O}$ horário escolhido para essa representação foi às $15 \mathrm{~h} 00$.

No cenário original (simulado no programa ENVImet), sem modificações (Figura 15a), é possível perceber que o ar é mais aquecido no setor à direita (norte). Os valores de $\mathrm{Ta}$ na rua de estudo, às $15 \mathrm{~h} 00$, variaram entre $30,8{ }^{\circ} \mathrm{C}$ e $33,5{ }^{\circ} \mathrm{C}$. No primeiro cenário foram implantadas árvores de 15 $m$ de altura e copa densa ao longo da Rua Firminiano Pinto, em apenas um lado da rua (Figura 15b). Nesta situação a variação de temperatura do ar ao longo da rua foi de $30,4{ }^{\circ} \mathrm{C}$ até $33,3^{\circ} \mathrm{C}$. Foi verificada também a influência da arborização nos dois lados da rua, caracterizando um corredor verde (Figura 15c). Neste caso, às $15 \mathrm{~h} 00$ percebe-se que na rua de estudo a temperatura do ar variou entre $29,8^{\circ} \mathrm{C}$ e $33,5^{\circ} \mathrm{C}$. Em todo o trecho da rua a redução média da Ta a partir do cenário 1 e 2 foi de $0,8{ }^{\circ} \mathrm{C}$ e $1,2{ }^{\circ} \mathrm{C}$ respectivamente.

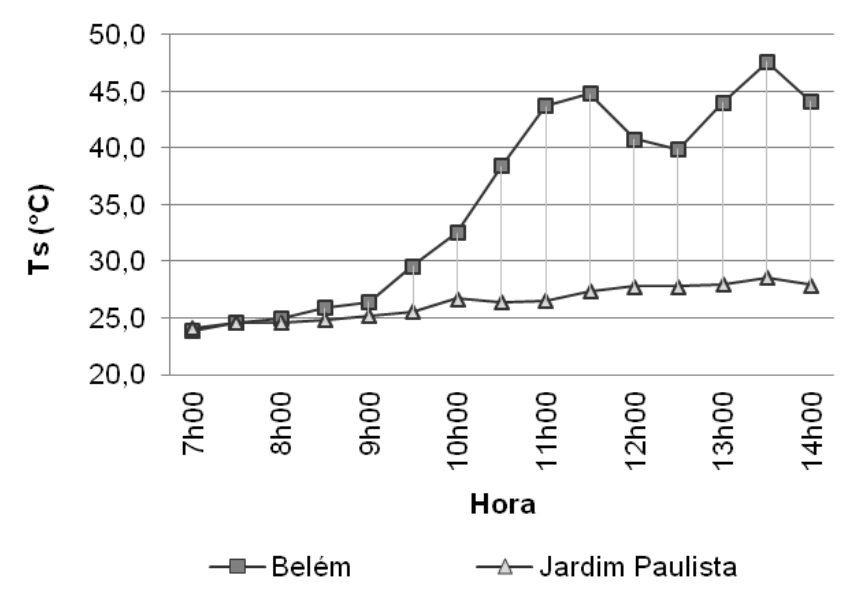

Figura 13 - Comparações entre valores de temperatura de superfície (Ts) 


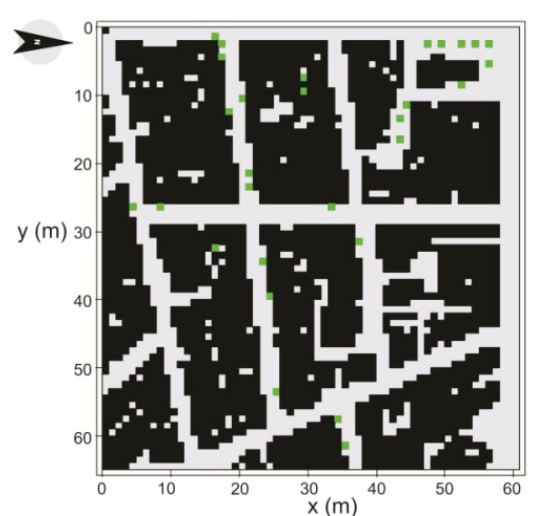

(a) Cenário original

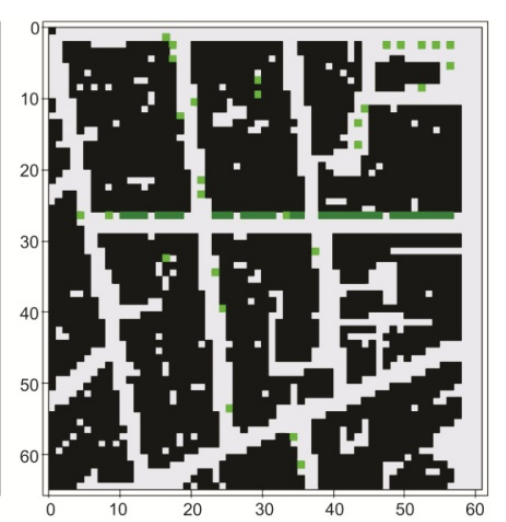

(b) Cenário 1

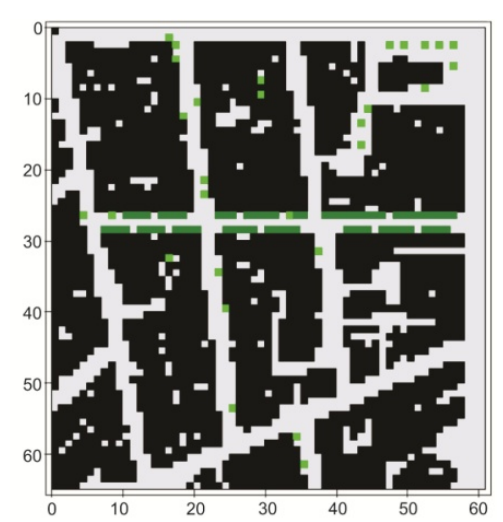

(c) Cenário 2

Figura 14 - Planta baixa da fração urbana do bairro Belém

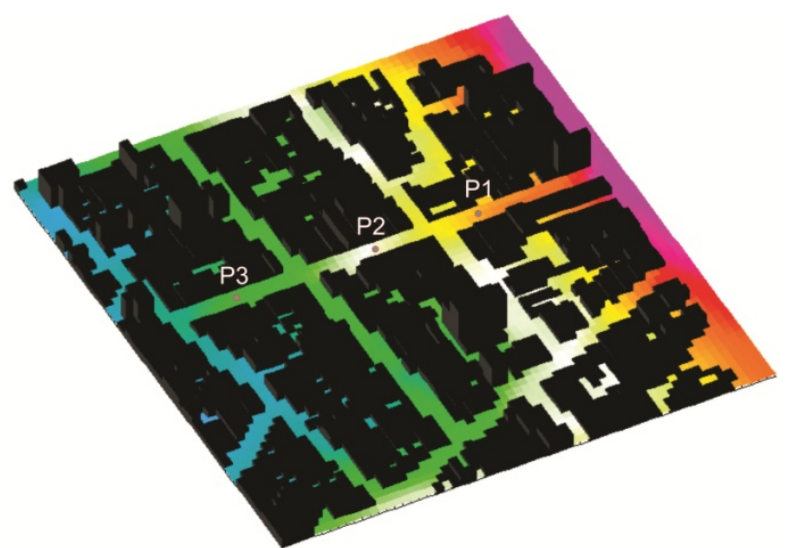

(a) Cenário original

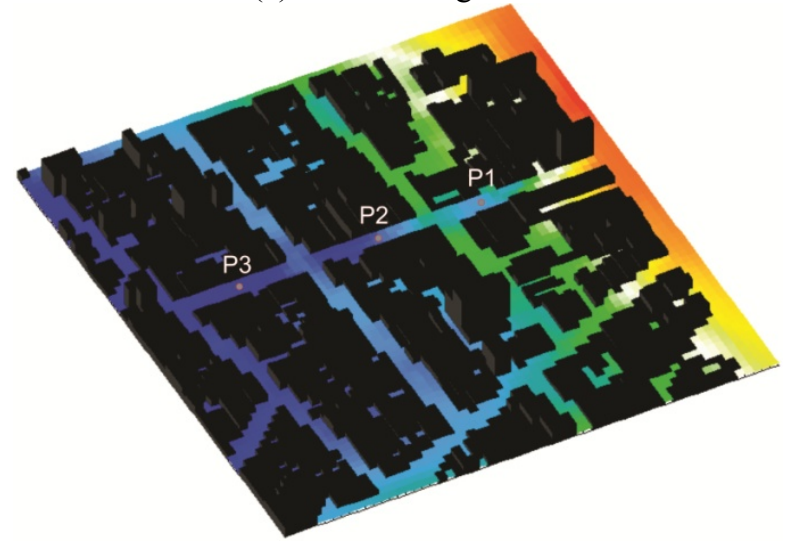

(c) Cenário 2

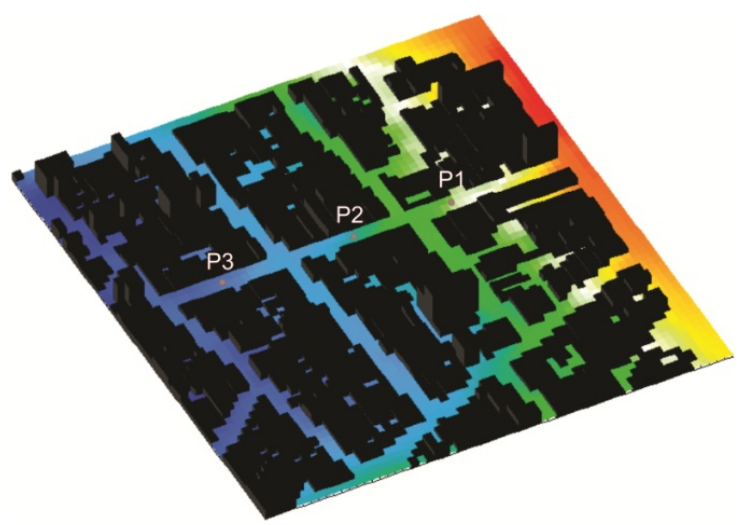

(b) Cenário 1

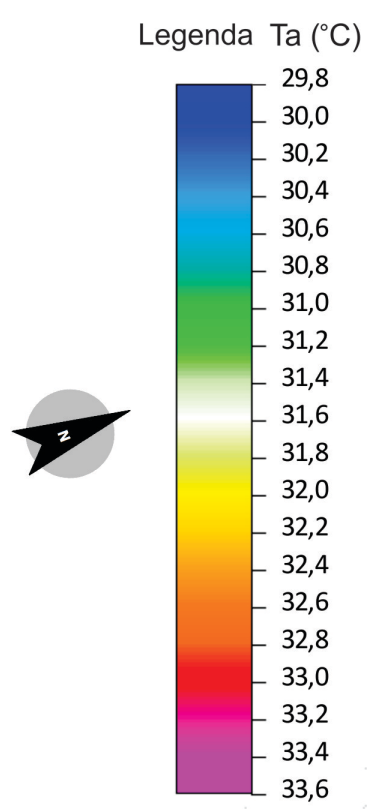

Figura 15 - Vista em três dimensões da fração urbana do bairro Belém

Além do ponto no qual ocorreu o monitoramento (P1), foram alocados pontos específicos para uma análise mais abrangente. O ponto da quadra central é chamado de $\mathrm{P} 2$, e o ponto à esquerda é chamado de P3 (Figura 16).
No período considerado para análise, com arborização apenas de um lado da via (cenário 1), a Ta média no ponto $\mathrm{P} 1$ poderia ser reduzida em 0,6 ${ }^{\circ} \mathrm{C}$ em relação ao cenário original simulado, enquanto no cenário 2 , com a proposta de 
arborização em ambos os lados da via, a Ta média poderia ser reduzida em $1,4{ }^{\circ} \mathrm{C}$. A redução mais significativa, para os dois cenários, ocorreria às 15h00, com diferença negativa de $1,0{ }^{\circ} \mathrm{C}$ no cenário $1 \mathrm{e}$ de $1,8{ }^{\circ} \mathrm{C}$ no cenário 2 (Tabela 8 ).

$\mathrm{Na}$ quadra central (P2), para o período diurno analisado, a redução da Ta média foi de $0,6{ }^{\circ} \mathrm{C}$ para o cenário 1 e de $1,1{ }^{\circ} \mathrm{C}$ para o cenário 2 , ocorrendo, neste último cenário, a máxima diferença de Ta às $15 \mathrm{~h} 00$, com $1,5^{\circ} \mathrm{C}$ (Tabela 9).

No ponto 3 a Ta média simulada no cenário original foi menor em relação às outras duas quadras que compõem a rua de estudo. As reduções nos valores de temperatura do ar também foram menos significativas em relação à mudança nos cenários proposto nos pontos $\mathrm{P} 1$ e $\mathrm{P} 2$, sendo estas de $0,5{ }^{\circ} \mathrm{C}$ e de $0,9{ }^{\circ} \mathrm{C}$ nos cenários 1 e 2 respectivamente. A redução máxima de Ta ocorreu, novamente, às $15 \mathrm{~h} 00$ no cenário 2 , com $1,2{ }^{\circ} \mathrm{C}$ (Tabela 10).

$\mathrm{Na}$ Tabela 11 constam as médias de temperatura do ar para o ponto P1 no Belém (dados simulados) e para a medição em campo realizada no Jardim Paulista, considerando o período analisado, além dos valores de fator de visão do céu (FVC). O valor de FVC para o cenário original no Belém e no Jardim Paulista foi obtido a partir de imagem tirada com lente olho de peixe $8 \mathrm{~mm}$ acoplada a uma câmera Nikon D80, editada, posteriormente, no programa Photoshop (Figura 17). O cálculo do índice foi realizado no programa RayMan. Para os cenários 1 e 2, os valores de FVC do ponto P1 foram obtidos no programa ENVI-met.

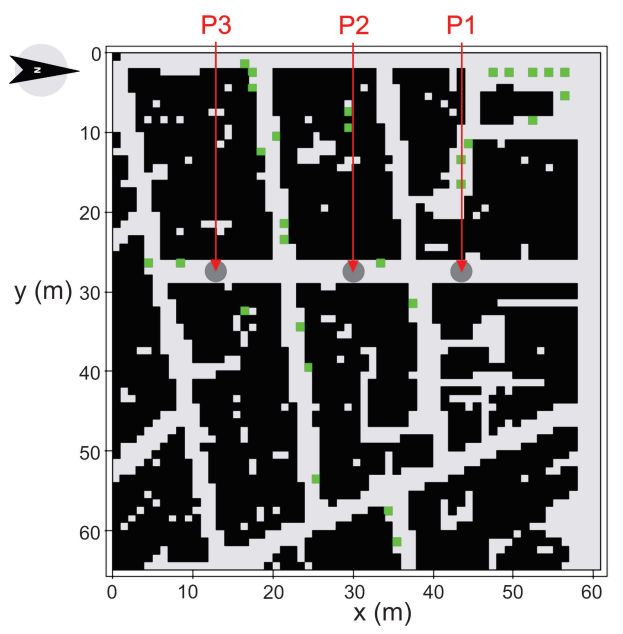

Figura 16 - Localização dos pontos P1, P2 e P3

Tabela 8 - Médias horárias de temperatura do ar para o ponto P1

\begin{tabular}{c|c|c|c|c|c}
\hline P1 & cenário original & cenário 1 & dif. cen. 1 & cenário 2 & dif. cen. 2 \\
\hline $10 \mathrm{~h} 00$ & 28,1 & 27,7 & 0,4 & 26,9 & 1,1 \\
\hline $11 \mathrm{~h} 00$ & 29,3 & 28,9 & 0,4 & 28,0 & 1,3 \\
\hline $12 \mathrm{~h} 00$ & 30,5 & 30,1 & 0,4 & 29,1 & 1,4 \\
\hline $13 \mathrm{~h} 00$ & 31,5 & 31,0 & 0,5 & 30,5 & 1,0 \\
\hline $14 \mathrm{~h} 00$ & 32,1 & 31,3 & 0,8 & 30,5 & 1,7 \\
\hline $15 \mathrm{~h} 00$ & 32,3 & 31,3 & 1,0 & 30,5 & 1,8 \\
\hline média & 30,6 & 30,1 & 0,6 & 29,3 & 1,4 \\
\hline
\end{tabular}

Tabela 9 - Médias horárias de temperatura do ar para o ponto P2

\begin{tabular}{c|c|c|c|c|c}
\hline P2 & cenário original & cenário 1 & dif. cen. 1 & cenário 2 & dif. cen. 2 \\
\hline $10 \mathrm{~h} 00$ & 27,7 & 27,3 & 0,4 & 26,7 & 1,0 \\
\hline $11 \mathrm{~h} 00$ & 28,8 & 28,3 & 0,4 & 27,7 & 1,1 \\
\hline $12 \mathrm{~h} 00$ & 29,8 & 29,3 & 0,5 & 28,7 & 1,1 \\
\hline $13 \mathrm{~h} 00$ & 30,7 & 30,2 & 0,5 & 29,8 & 0,9 \\
\hline $14 \mathrm{~h} 00$ & 31,3 & 30,6 & 0,8 & 30,0 & 1,3 \\
\hline 15h00 & 31,5 & 30,7 & 0,9 & 30,1 & 1,5 \\
\hline média & 30,0 & 29,4 & 0,6 & 28,8 & 1,1 \\
\hline
\end{tabular}

154 Minella, F. C. O.; Honjo, S.; Krüger, E. L. 
Tabela 10 - Médias horárias de temperatura do ar para o ponto P3

\begin{tabular}{c|l|l|l|l|l}
\hline P3 & cenário original & cenário 1 & dif. cen. 1 & cenário 2 & dif. cen. 2 \\
\hline $10 \mathrm{~h} 00$ & 27,4 & 27,1 & 0,3 & 26,6 & 0,8 \\
\hline $11 \mathrm{~h} 00$ & 28,4 & 28,0 & 0,4 & 27,5 & 0,9 \\
\hline $12 \mathrm{~h} 00$ & 29,3 & 28,8 & 0,4 & 28,3 & 0,9 \\
\hline $13 \mathrm{~h} 00$ & 30,1 & 29,6 & 0,5 & 29,3 & 0,8 \\
\hline $14 \mathrm{~h} 00$ & 30,8 & 30,1 & 0,6 & 29,7 & 1,1 \\
\hline $15 \mathrm{~h} 00$ & 31,0 & 30,3 & 0,7 & 29,8 & 1,2 \\
\hline média & 29,5 & 29,0 & 0,5 & 28,5 & 0,9 \\
\hline
\end{tabular}

Tabela 11 - Médias horárias de temperatura do ar

\begin{tabular}{|c|c|c|c|c|}
\hline \multirow{3}{*}{$22 / 02 / 2011$} & \multicolumn{3}{|c|}{ Belém - P1 } & \multirow{3}{*}{$\begin{array}{c}\text { Jd Paulista } \\
\text { (dados medidos) }\end{array}$} \\
\hline & cenário original & cenário 1 & cenário 2 & \\
\hline & (dados simulados) & (dados simulados) & (dados simulados) & \\
\hline Ta média $\left({ }^{\circ} \mathrm{C}\right)$ & 30,6 & 30,1 & 29,3 & 29,2 \\
\hline FVC aproximado & 0,6 & 0,5 & 0,2 & 0,2 \\
\hline
\end{tabular}

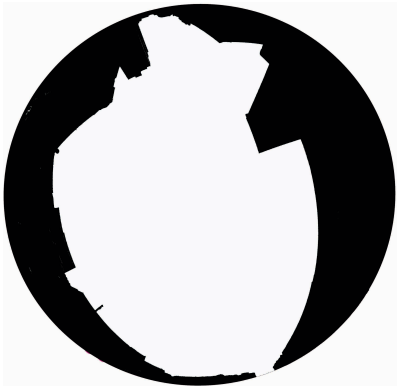

(a) Belém

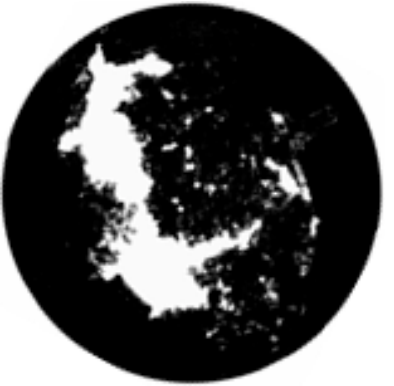

(b) Jardim Paulista

Figura 17 - Imagens olho de peixe dos pontos

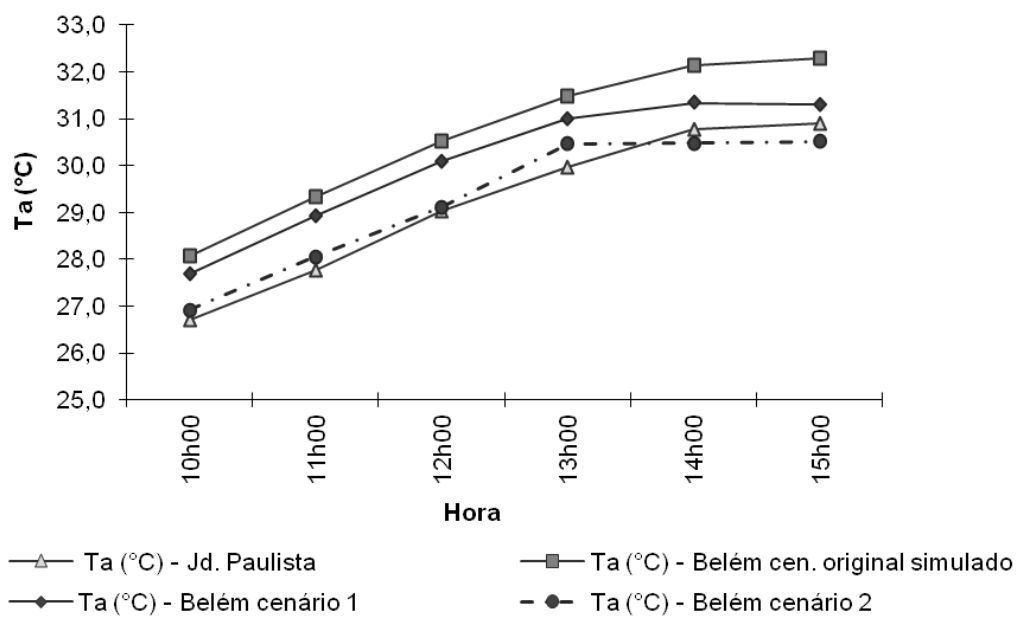

Figura 18 - Comparações entre valores de temperatura do ar (Ta)

Considerando o cenário 1 , com arborização apenas em um lado da rua e FVC aproximado de 0,5, a redução de $0,5{ }^{\circ} \mathrm{C}$ na Ta média possivelmente amenizaria o desconforto térmico. No entanto, é no cenário 2, com árvores em ambos os lados da via e FVC aproximado de 0,2, que haveria uma redução da Ta mais significativa, correspondente a $1,3{ }^{\circ} \mathrm{C}$.
Nota-se que a aproximação dos valores de FVC do cenário 2 no Belém com o valor obtido no Jardim Paulista acarretou em valores próximos de temperatura do ar, principalmente das $10 \mathrm{~h} 00$ até as $12 \mathrm{~h} 00$ (Figura 18), sugerindo uma relação entre essas variáveis. 
Considerando toda a fração urbana modelada, e não apenas o ponto medido, a temperatura do ar média no período de análise no cenário original foi de $30,1{ }^{\circ} \mathrm{C}$, enquanto nos cenários 1 e 2 a temperatura do ar no mesmo período foi de 29,7 e $29,5{ }^{\circ} \mathrm{C}$, com diferenças de 0,4 e $0,6{ }^{\circ} \mathrm{C}$, respectivamente.

\section{Conclusões}

A análise dos resultados corroborou a premissa inicial de que a fração urbana do Belém apresentaria temperaturas mais altas que no Jardim Paulista devido às características urbanas do bairro, em concordância com o mapa termal apresentado inicialmente (Figura 1). Entre os fatores que influenciam para valores de temperatura do ar mais baixos no Jardim Paulista citam-se menor valor de fator de visão do céu e arborização significativa. Destaca-se este último fator, que além do aspecto psicológico atrelado a ambientes externos arborizados, torna a rua monitorada (Rua Oscar Freire) mais confortável termicamente, favorecendo seu uso por parte dos transeuntes.

$\mathrm{Na}$ região do Belém, considerando o período monitorado, o ambiente térmico é prejudicado em decorrência de haver pouco sombreamento, acarretando valores altos de radiação solar incidente e de temperatura de superfície, e, consequentemente, tornando o local propenso a situações de maior estresse térmico.

A estratégia de redução da temperatura ambiente por meio da arborização formando um corredor verde mostrou uma significativa melhora no ambiente térmico do ponto monitorado, com redução de até $1,8{ }^{\circ} \mathrm{C}$ às $15 \mathrm{~h} 00$. Para todo o trecho da rua, a redução média da Ta no período de análise foi de $1,2{ }^{\circ} \mathrm{C}$. Apesar das diferenças metodológicas, valor semelhante $\left(1,1{ }^{\circ} \mathrm{C}\right)$ foi verificado na pesquisa realizada por Spangenberg et al. (2008) para a cidade de São Paulo. Em tal estudo, com base na medição microclimática realizada no centro da cidade, em um dia de verão, no período entre as $7 \mathrm{~h} 00$ e as $19 \mathrm{~h} 00$, foi realizado um estudo paramétrico com quatro quadras, sendo considerados dois cenários, nos quais foram utilizadas árvores com diferentes densidades, possibilitando, então, a análise da forma de atenuação da radiação solar nesses dois casos.

No presente estudo, quando considerada a arborização apenas de um lado da rua, a melhora foi menos significativa $\left(0,6{ }^{\circ} \mathrm{C}\right)$. Nesse caso, poderiam ser utilizadas estratégias combinadas, com modificações do albedo, da própria forma urbana (na qual a ação do vento e o sombreamento gerado poderiam potencializar a redução de temperatura do ar) e ainda adição de áreas gramadas. Esta última estratégia ainda auxiliaria a evitar inundações, fenômeno frequente na região em épocas de chuvas. Em ambientes urbanos, sugere-se também a utilização de árvores que perdem a folhagem no período de inverno, já que as condições térmicas almejadas diferem das de verão.

No tocante ao efeito da vegetação em toda a fração compreendida na simulação, o aumento em aproximadamente $2 \%$ de vegetação arbórea no cenário 2 em relação ao cenário original reduziu em $\quad 0,6 \quad{ }^{\circ} \mathrm{C} \quad$ a temperatura ambiente. Desconsiderando o trecho de rua no qual as modificações foram pontuais, a redução seria de $0,5{ }^{\circ} \mathrm{C} . \mathrm{Ng}$ et al. (2012) também perceberam o efeito benéfico da arborização. Em estudo paramétrico realizado em Hong Kong, localidade com clima subtropical úmido, foram testados os efeitos da forma urbana e da vegetação no microclima, totalizando 33 casos de estudo. Os dados foram analisados às $15 \mathrm{~h} 00$. A inserção de árvores cobrindo $16 \%$ da área de estudo pode reduzir em $0,4{ }^{\circ} \mathrm{C}$, enquanto em uma cobertura vegetal de $56 \%$ a redução pode ser de $1,8{ }^{\circ} \mathrm{C}$. Ressalta-se que deve haver cautela quanto às comparações entre pesquisas, devido à possibilidade de haver diferenças nos procedimentos metodológicos aplicados.

Embora a influência da vegetação seja mais localizada (GIVONI, 1991), o efeito positivo da inserção de arborização poderia ser potencializado com a implantação da vegetação de forma distribuída, ao invés de concentrar em apenas uma única área ou via. Essa observação também foi reforçada por Wong e Steve (2008), na análise das modificações na temperatura do ar no campus da National University of Singapore, em decorrência da implantação do Plano Diretor de 2005, o qual propunha novas edificações ao campus (mais de $56 \%$ de novas edificações) e, consequentemente, diminuição das áreas verdes (redução na taxa vegetada de $55 \%$ para $52 \%$ ). O resultado a partir do ENVI-met mostrou que, com a construção das novas edificações e consequente redução das áreas verdes, a Ta aumentaria cerca $1{ }^{\circ} \mathrm{C}$. A inserção de árvores mostra uma redução, mas os valores de Ta ainda continuariam altos, sendo mais significativo o efeito de resfriamento da arborização no período noturno.

A densidade da copa, segundo Shinzato (2009), que investigou, com o auxílio do ENVI-met, a influência da arborização no microclima para uma área central da cidade de São Paulo, é o fator primordial para a qualidade da sombra. Salienta-se

156 Minella, F. C. O.; Honjo, S.; Krüger, E. L. 
que, além desse papel, a escolha de árvores com determinados padrões e valores de densidade de área foliar influencia na permeabilidade dos ventos, podendo afetar a sensação térmica dos transeuntes.

O programa ENVI-met, embora apresente algumas limitações, como, por exemplo, a modelagem ortogonal (que acaba por simplificar a forma urbana), padronização da temperatura interna das edificações a um valor constante e desprezo do efeito de inércia térmica da massa edificada, mostrou-se um programa eficaz para o estudo proposto. O programa tem sido empregado em diversos estudos, no entanto são poucos os que utilizam testes estatísticos para a validação dos dados. Em revisão realizada, apenas o estudo de Spangenberg et al. (2008) relatou um coeficiente de determinação de 0,74 entre os dados medidos e simulados; os testes aqui aplicados apresentaram resultados superiores $(0,91)$.

Neste estudo foi possível perceber que a arborização exerce influência na temperatura do ar, especialmente na projeção das sombras das copas, havendo, portanto, uma limitação quanto a sua abrangência no campo térmico urbano. Desse modo, recomenda-se que a vegetação arbórea seja implantada no ambiente urbano de forma a oferecer opções de trajetos aos transeuntes. Recomenda-se, também, dedicar atenção à densidade da copa e à espécie da árvore. Além disso, ressalta-se que a utilização de simulações computacionais, embora não seja uma prática comum nos órgãos e institutos de planejamento urbano, poderia auxiliar nas decisões de planejamento urbano, criando maior vínculo entre a climatologia e o urbanismo.

É importante reiterar que os resultados encontrados nesta pesquisa referem-se apenas a um contexto climático particular e a um período diurno específico. Mesmo assim, o presente estudo pode servir como base para situações climáticas semelhantes e abordagens futuras sobre o tema.

\section{Referências}

\section{ANTONUCCI, D. Morfologia Urbana e}

Legislação Urbanística: estudo de setores de bairros na cidade de São Paulo. São Paulo, 2005. Tese (Doutorado em Arquitetura e Urbanismo, Estruturas Ambientais Urbanas) - Faculdade de Arquitetura e Urbanismo, Universidade de São Paulo, São Paulo, 2005.
ASSIS, E.S. Impactos da Forma Urbana na Mudança Climática: método para a previsão do comportamento térmico e melhoria de desempenho do ambiente urbano. São Paulo, 2000. Tese (Doutorado em Arquitetura e Urbanismo) Faculdade de Arquitetura e Urbanismo, Universidade de São Paulo, São Paulo, 2000.

BRANDÃO, R. As interações Espaciais Urbanas e o Clima. São Paulo, 2009. Tese (Doutorado em Arquitetura e Urbanismo) - Faculdade de Arquitetura e Urbanismo, Universidade de São Paulo, São Paulo, 2009.

BRUSE, M. ENVI-Met Website. Desponível em: $<$ http://www.envi-met.com>. Acesso em: $22 \mathrm{dez}$. 2012.

BRUSE, M.; FLEER, H. Simulating SurfacePlant-Air Interactions Inside Urban Environments with a Three Dimensional Numerical Model.

Environmental Software and Modeling, v. 13, n. 3, p. 373-384, out. 1998 .

CAMPBELL, S. Application Note: weather station siting and installation tools. Logan: Campbell Scientific, Inc., 1997.

DEPARTAMENTO DE ESTATÍSTICA E PRODUÇÃO DE INFORMAÇÃO. Mapa de Uso e Ocupação do Solo da Região Metropolitana de São Paulo e Bacia Hidrográfica do Alto Tietê. São Paulo: DIPRO, 2011.

FELDMAN, S. Planejamento e Zoneamento: São Paulo 1947/1972. São Paulo: EDUSP; FAPEST, 2005.

FREITAS, E.; DIAS, P. Alguns Efeitos de Áreas Urbanas na Geração de Uma Ilha de Calor.

Revista Brasileira de Meteorologia, v. 20, n. 3, p. 355-366, 2005.

GIVONI, B. Impact of Planted Areas on Urban Environmental Quality: a review. Atmospheric Environment, v. 5, n. 3, p. 289-299, 1991.

HÖPPE, P. The Physiological Equivalent Temperature: a index for the biometeorological assessment of the thermal environment.

International Journal of Biometeorology, Dordrecht, v. 43, p. 71-75, 1999.

INSTITUTO BRASILEIRO DE GEOGRAFIA E ESTATÍSTICA. Censo 2000. Disponível em: $<$ http://www.ibge.gov.br/home/estatistica/populaca o/censo2000/universo.php?tipo $=31$ \&paginaatual $=1$ \&uf=35\&letra $=\mathrm{S}>$. Acesso em: 21 jun. 2011.

INTERNATIONAL ORGANIZATION FOR STANDARDIZATION. ISO 7726: ergonomics of the thermal environment: instruments of measuring physycal quantities. Switzerland, 1998. 
INTERNATIONAL ORGANIZATION FOR STANDARDIZATION. ISO 8996: ergonomics of the thermal environment: determination of metabolic rate. Switzerland, 2004.

LOMBARDO, M. A. Ilha de Calor nas Metrópoles: o exemplo de São Paulo. São Paulo: HUCITEC, 1985.

MACEDO, S. São Paulo, Paisagem e Habitação Verticalizada: os espaços livres como elementos de desenho urbano. São Paulo, 1988. Tese (Doutorado em Arquitetura e Urbanismo, Estruturas Ambientais Urbanas) - Faculdade de Arquitetura e Urbanismo, Universidade de São Paulo, São Paulo, 1988.

MATZARAKIS, A.; RUTZ, F.; MAYER, H. Modelling Radiation Fluxes in Simple and Complex Environments: application of the RayMan model. International Journal Biometeorolody,. v. 51, n. 4, p. 323-334, 2007.

MONTEIRO, L. M.; ALUCCI, M. P. Conforto Térmico em Espaços Abertos Com Diferentes Abrangências Microclimáticas: parte 2: proposição de calibração de modelos preditivos. In: ENCONTRO NACIONAL, 8.; ENCONTRO LATINO-AMERICANO SOBRE CONFORTO NO AMBIENTE CONSTRUIIDO, 5., Ouro Preto, 2007. Anais... Ouro Preto: ANTAC, 2007.

$\mathrm{NG}$, E. et al. A Study on the Cooling Effects of Greening in High-Density City: an experience from Hong Kong. Building Environment, v. 47, p. 256-271, jan. 2012.

OKE, T. R. Boundary Layer Climates. $2^{\text {nd }}$. London: Routledge, 1987.

SÃO PAULO. Secretária Municipal de Planejamento. Atlas Ambiental do Município de São Paulo: fase I: diagnósticos e bases para a definição de políticas públicas para as áreas verdes no município de São Paulo.São Paulo: SVMA, SEMPLA, 2002. Relatório Final.

SÃO PAULO. Secretaria Municipal do Verde e Meio Ambiente. Atlas Ambiental do Município de São Paulo: o verde, o território, o ser humano: diagnóstico e bases para a definição de políticas públicas para as áreas verdes do município de São Paulo. São Paulo: SVMA, 2004.
SÃO PAULO. Lei $\mathbf{n}^{\mathbf{0}} \mathbf{7 . 8 0 5}$, de 01 de novembro de 1972, dispõe sobre o parcelamento, uso e ocupação do solo do Município, e dá outras providências. Disponível em:

$<\mathrm{http}$ ://www.prefeitura.sp.gov.br/cidade/secretaria s/habitacao/plantas_on_line/legislacao/index.php? $\mathrm{p}=5679>$. Acesso em: $\overline{1}$ jan. 2011.

SPANGENBERG, J. et al. Simulation of the Influence of Vegetation on Microclimate and Thermal Comfort: in the city of São Paulo. Revista SBAU, Piracicaba, v. 3, n. 2, p. 1-19, 2008.

SHINZATO, P. Impacto da Vegetação nos Microclimas Urbanos. São Paulo, 2009. Dissertação (Mestrado em Arquitetura) Faculdade de Arquitetura e Urbanismo, Universidade de São Paulo, São Paulo, 2009.

SOMEKH, N. A Cidade Que Não Pode Parar: planos urbanísticos de São Paulo no século XX. São Paulo: Fundo Mackenzie de Pesquisa, 2002.

TARIFA, J.; AZEVEDO, T. Os Climas na Cidade de São Paulo: teoria e prática. São Paulo: FFLCH-USP, 2001.

THORSSON, S. et al. Different Methods for Estimating the Mean Radiant Temperature in an Outdoor Urban Setting. International Journal of Climatology, v. 27, n. 14, p. 1983-1993, 2007.

UNITED NATIONS. World Urbanization

Prospects: the 2011 revision. New York, 2012.

WIERINGA, J. et al. New Revision of Davenport Roughness Classification. In: EUROPEAN \& AFRICAN CONFERENCE ON WIND ENGINEERING, 3., Eindhoven, 2001. Proceedings... Eindhoven, 2001.

WONG, N. H.; STEVE, K. J. GIS-Based Greenery Evaluation on Campus Master Plan. Landscape Urban Plan, v. 84, n. 2, p. 166-182, fev. 2008.

\section{Agradecimentos}

Os autores agradecem à Universidade de Genebra, à Capes, pela concessão da bolsa de doutorado, e ao $\mathrm{CNPq}$, pela concessão do Projeto Universal 474358/2007-0, Universal 2007 Faixa B.

\author{
Revista Ambiente Construído \\ Associação Nacional de Tecnologia do Ambiente Construído \\ Av. Osvaldo Aranha, $99-3^{\circ}$ andar, Centro \\ Porto Alegre - RS - Brasil \\ CEP $90035-190$ \\ Telefone: +55 (51) 3308-4084 \\ Fax: +55 (51) 3308-4054 \\ www.seer.ufrgs.br/ambienteconstruido \\ E-mail: ambienteconstruido@ufrgs.br
}

158 Minella, F. C. O.; Honjo, S.; Krüger, E. L. 